\title{
XIV,
}

Aus der psychiatrischen Klinik der Königlichen Charité (Prof. Jolly).

\section{Statistisches und Klinisches zur Kenntniss der paralytischen Geistesstörung beim weiblichen Geschlecht.}

\author{
Von \\ Dr. R. Wollenberg, \\ früher Assistent der Klinik, jetzt Privatdocent und Oberarzt der psychiatrisehen \\ und Nervenklinik zu Halle a. S.
}

In den letzten 24 Jahren hat sich eine Anzahl von Forschern verschiedener Nationalität mit dem Specialstadium der progressiven Paralyse der Frauen beschäftigt. - Die Verschiedenheiten der Körperconstitution, der geistigen Anlagen und der allgemeinen Lebensbedingungen, welche bei den beiden Geschlechtern vorbanden sind, schienen die Hoffnung za rechtfertigen, dass es möglich sein würde, durch eine vergleichende statistische und klinische Betrachtung einer grösseren Anzahl geẹigneter Fälle zur Klärung einiger noch controverser Fragen wesentlich beizutragen. Hierbei stand naturgemäss im Vordergrunde des Interesses die weitere Aufklärung der bei der progressiven Paralyse in Betracht kommenden ätiologischen Momente, über welche bekanntlich noch Meinungsverschiedenheiten herrschen; sodann erschien aber auch die Möglichkeit nicht ausgeschlossen, dass die klinische Betrachtung uns Gesichtspunkte kennen lehren würde, welche die Abgrenzung einer besonderen "weiblichen Paralyse" gestatteten. - Die letztere Erwartung bat sich nicht erfüllt: Wir haben zwar gewisse Züge kennen gelernt, welche der Paralyse der Frauen eine besondere Färbung verleihen, wir müssen aber heute erklären, dass im Wesentlichen das Krankheitsbild bei beiden Geschlechtern 
ein identisches ist. Hingegen hat die statistische Forschung ein etwas positiveres Resultat insofern gehabt, als durch sie eine richtigere Beurtheilung der in Betracht kommenden ätiologischen Momente ermöglicht worden ist. So begegnet heute die Lehre von der grossen Bedeutung der Syphilis für die Entstehung der Paralyse nur noch vereinzeltem Widerspruch; daneben sind aber auch die anderen Schädlichkeiten als Excesse aller Art, psychische Ursachen, Heredität, neuropathische Anlage etc. zu ihrem Recht gekommen und es ist gerade ein Verdienst einiger neverer, unten näber zu besprechender Arbeiten, auf die Häufigkeit and Wichtigkeit der Combination mehrerer ätiologischer Momente mit gebührendem Nachdruck hingewiesen zu haben.

Bei dieser Sachlage muss die Beibringung weiteren entsprechend verarbeiteten und hinreichend umfangreichen Beobachtungsmaterials auch jetzt noch - trotz der bereits vorhandenen überaus reichen Literatur dieses Gegenstandes - als eine lohnende Aufgabe bezeichnet werden. Auch wenn sich dieses Material - wie das meinige nur aus Kranken weiblichen Geschlechts zusammensetzt, lassen sich bei der oben für beide Geschlechter constatirten principiellen Gleichartigkeit des Krankheitsbildes daraus Schlüsse von allgemeiner Gültigkeit ziehen. Ausserdem sind es aber einige specielle klinisehe Fragen, deren weitere Erörterung nach dem Studium der vorhandenen Literatur nicht ohne Interesse erscheint; es sei nur hingewiesen auf gewisse Varietäten des psychischen Krankheitsbildes, sodann auf die Verschiedenheiten der Rückenmarksbetheiligung, soweit sich dieselben klinisch nachweisen lassen, endlich auf die Differentialdiagnose zwischen paralytischen und anderen organischen Gehirnerkrankungen.

Andererseits darf nicht verkannt werden, dass das Arbeiten mit grossen Zahlen, wie Thomsen*) mit Recht hervorhebt, auch seine Nachtheile hat. Naturgemäss können die Anstalten mit so lebhafter Krankenbewegung wie die Berliner Charité ihre Kranken nur ausnahmsweise so lange behalten, wie das zur Feststellung mancher wichtiger Punkte - insbesondere des gesammten Krankheitsverlaufes - erforderlich ist. Aus der relativen Kürze der Beobachtungsmöglichkeit und der Schwierigkeit, in allen Fällen die nothwendigen Anamnestica rasch zu beschaffen, ergiebt sich mit Nothwendigkeit, dass nicht alle Krankengeschichten so lückenlos sein können, wie in einer weniger frequentirten Anstalt, in der die Kranken mit wenigen

*) Thomsen, Ueber die practische Bedeutung der Syphilis-Paralysefrage. Allgem. Zeitsohr. für Psych. Bd. 46. S. 619. 
Ausnahmen durch die Angehörigen oder andere orientirte Personen abgeliefert werden, und in der sie längere Zeit - meist bis zum Tode - mit Musse beobachtet werden können.

Immerhin bleibt aber auch im ersteren Falle die grosse Mehrzahl der Fälle, wenn auch vielfach mit einiger Beschränkung, verwerthbar, so dass eine grosse Statistik unter allen Umständen erwünscht ist. Ich befand mich ausserdem - Dank dem freundlichen Entgegenkommen des Directors der Dalldofer Anstalt, Herrn Gebeimrath Sander und des Oberarztes daselbst, Herrn Dr. König, - in der Lage, das Schicksal meiner aus der Charité zum allergrössten Theil nach Dalldorf überführten Kranken dort weiter verfolgen und die Krankengeschichten, soweit es wünschenswerth war, an der Hand der Dalldorfer Journale ergänzen zu können.

Aus der Literatur führe ich zunächst diejenigen Arbeiten an, welche speciell die Paralyse beim weiblichen Geschlecht behandeln, und auf die zum Theil weiterhin zurückzukommen sein wird.

Der Erste, welcher eine zusammenhängende Darstellung des Gegenstandes gab, war Sander*), Derselbe hat in den Jahren 1865 bis 1868 incl. 158 paralytische Männer und 15 paralytische Frauen aus der Charité entlassen; das Verhältniss der beiden Geschlechter stellt sich also wie 10,5:1 oder bei Zugrundelegung einiger von anderen Beobachtern jener Zeit angestellter Berechnungen wie $7,5: 1$. Was das Alter betrifft, so fand Sander dieses bei den Fraven im Allgemeinen höher als bei den Männern; die meisten weiblichen Paralysen waren über 40 , keine unter 30 Jahren, und zeichneten sich zum grössten Theil durch eine vorzeitige Decrepidität aus.

Im Uebrigen fand $\mathrm{S} a \mathrm{nder}$ in klinischer und anatomischer $\mathrm{Be}$ ziehung keine wesentlichen Unterschiede bei beiden Geschlechtern, doch betonte er bereits den ruhigeren, milderen, weniger offensiven Charakter der weiblichen Paralyse, den langsameren Verlauf derselben und die entsprechend den weiblichen Eigenthümlichkeiten modificirte Färbung der Grössenideen. Er meint ferner bei den Frauen die paralytischen Anfälle seltener und die pathologisch-anatomischen Veränderungen weniger ausgesprochen gefunden zu haben. Endlich ist noch von Interesse, dass er darauf hinwies, wie die Paralyse nicht nur überhaupt im Zunehmen zu sein, sondern insbesondere auch

*) W. Sander, Die paralytische Geistesstörung beim weiblichen Geschleoht. Berliner kl. Wochensohr. 1870. No. 7, S, 81. 
bei den Weibern sich mehr als früher und zwar auch im Verhältniss zu den Männern auszubreiten scheine.

Aus dem Jahre 1872 ist eine kleine Arbeit von Peyser*) zu erwähnen, welche zwei betreffende Krankengeschichten aus der Charité und auch einige allgemeine Bemerkungen über die Paralyse der Frauen enthält.

Es folgt ein Aufsatz von Krafft-Ebing**) vom Jahre 1877, in welchem 80 Fälle von weiblicher Paralyse hauptsächlich hinsichtlich der Aetiologie untersucht und mit einer entsprechenden Zahl männlicher Kranker verglichen werden. - Der Verfasser betont auf Grund dieser Zusammenstellung die Bedeutung der das Gehirn erschöpfenden Schädlichkeiten für die Paralyse überhaupt und "die geringere Resistenzfähigkeit des weiblichen Geschlechtes, wo jene zur Geltung gelangen“. Ein besonders wichtiges ätiologisches Moment ist nach seinen Erfahrungen das Klimacterium, auf welches er das Ueberwiegen der weiblichen Paralytischen im Alter von 40-45 Jahren zurückführt. Die von ihm gefundene im Vergleich zu den Männern auffallend grosse Zahl der jugendlichen Fälle (zwischen 20 und 30 Jahren) erklärt Krafft-Ebing daraus, dass das Weib in Folge seiner schwächeren Constitution den erschöpfenden Einflüssen rascher erliege als der Mann. - Im Uebrigen stimmen seine Erfahrungen, insbesondere was die Daner und den allgemeinen Charakter der weiblichen Paralyse gegenüber der männlichen betrifft, mit denen Sander's überein. - Das Verbältniss zwischen Männern und Weibern berechnet er auf $8: 1$.

Die im folgenden Jahre erschienene Arbeit von Kornfeld ${ }^{* * * *}$ ), aus welcher sich beachtenswerthe neue Gesichtspunkte nicht ergeben, führe jch nur an. - Die Ansichten desselben sind von Jung bereits 1877 lritisirt und widerlegt worden, gelegentlich eines eingehenden, in der Versammlung des psychiatrischen Vereins zu Berlin am 15. December 1877 gehaltenen Vortrages $\dagger$ ). Jung hat ein Beobachtungs-

*) Peyser, Die allgemeine progressive Paralyse der Irren und ihr Anftreten beim weiblichen Geschlechte. Inang.-Diss. Berlin 1872.

**) v. Krafft-Ebing, Zur Kenntniss des paralytischen Irreseins beim weiblichen Geschlecht. Dieses Archiv VII. S. $182 \mathrm{ffi}$.

$\left.{ }^{* * *}\right)$ Kornfeld, Ueber Paralyse der Irren beim weiblichen Geschlecht. Berlin 1877 (mir im Original nicht zugänglich).

†) Jung, Ueber Paralyse der Frauen. Zeitschrift für Psychiatrie. Bd. 35. S. $235 \mathrm{ff}$. 
material von 45 diagnostisch einwandsfreien Fallen verwerthet und seine dabei gemachten Erfahrungen in einer Anzahl von Schlussfolgerungen zusammengefasst, von denen folgende uns besonders interessiren: Die Paralyse des weiblichen Geschlechtes nimmt in neuester Zeit in den unteren Ständen bei uns zu -; sie ist eine Krankheit des Klimacteriums; sie setzt eine individuelle Schwäche des Nervensystems und einen zu vasomotorischen Störungen geeigneten Boden voraus, auch spielt die Erblichkeit bei ihrem Entstehen eine grosse Rolle. Die Krankheit tritt beim Weibe vorwiegend zwischen dem 35. und 45. Lebensjahre, um rund 10 Jahre später als beim Manne auf. Sie dauert im Mittel 1-2 Jahre, verläuft selten stürmisch und schnell, and unterscheidet sich in Bezug auf die psychische Erscheinungsweise in nichts von der Paralyse des Mannes. Sie wird meist von einem kurzen melancholischen Stadium eingeleitet. Die paralytischen Frauen sind entweder kinderlos oder sie baben nur ein Kind oder die Kinder wurden todt geboren oder starben sehr jung.

Gegen einzelne dieser Sätze wurden in der sich unmittelbar anschliessenden Discussion Einwände erhoben, so betonten Ideler und Sander, dass der Satz von der Erkrankung der Frauen in einem späteren Lebnsalter für die Gegenwart seine Geltung zu verlieren beginne, und dass die Krankheitsdauer im Mittel eine längere sei als Jung angenommen. Jastrowitz wies auf die von Jung nicht gewürdigte ätiologische Bedeutung der Syphilis hin. - Uebereinstimmend wurde endlich allseitig constatirt, dass die Paralyse bei den Frauen der höheren Stände höchst selten sei. (Angaben von Filter, Laehr, Jung u. A.*)

Das Paralysenmaterial der weiblichen Abtheilung der Berliner psychiatrischen Klinik aus dem Jahre 1877 hat Sioli**) verarbeitet. Das absolute Verhältniss zwischen den Paralytischen beider Geschlechter stellt sich nach ihm wie (Frauen) 1 zu (Männer) 7.

Aus dem Jahre 1879 liegt eine Arbeit von Fritsch $\left.{ }^{* * *}\right)$ vor, welche sich auf die von 1876-1878 aufgenommenen Paralytiker (einer der Wiener Anstalten) bezieht. Das Verhältniss zwischen Weibern

*) Zeitschrift für Psychiatrio Bd. 35. S. 252 ff.

*) Sioli, Ueber die im Jahre 1877 aufgenommenen an allgemeiner Paralyse leidenden weiblichen Irren. Charité-Annalen IV. 1877. S. 455 (nach Westphal in Virchow-Hirsch referirt).

***) Fritsoh, Beitrag zor Kenntniss der progressiven Paralyse des weiblichen Geschleehts. Wiener medic. Presse 1879. 48. (nach Westphal in Virchow-Hirsch referirt). 
und Männern stellt sich auf 1:6 die Vertheilung auf die verschiedenen Altersstufen war für die Zeit vom 35.-45. Lebensjahre bei beiden Geschlechtern ungefähr die gleiche; dagegen fand ein relatives Ueberwiegen des späteren Alters bei den Männern statt. - 10 pCt. der paralytischen Weiber waren Prostituirte; der Heredität fiel nur eine geringe, hingegen dem Klimacterium eine bedeutende Rolle in der Aetiologie zu. Der Verlauf war bei Frauen ein länger hingezogener in Folge des Zurücktretens des tobsüchtigen Erregungzustandes.

1n einer im Jahre 1879 erschienenen Arbeit berichtet Adam*) über sieben Paralytische, unter denen sich die auffallend hohe Zahl von fünf Prostituirten befindet. - Remissionen sind in keinem Falle beobachtet.

Ferner entnehmen wir aus einem Aufsatze von Régis**) 1882, dass bei der Arbeiterbevölkerung des Seinedepartements das Verbältniss zwischen paralytischen Frauen und Männern wie 1:3 ist; dass ferner bei einer Verwerthung sämmtlicher Stände sich die männlichen Paralytischen mit 20,9 pCt., die weiblichen mit 2,5 pCt. betbeiligt erweisen, wäbrend bei ausschliesslicher Berücksichtigung der besseren Stände die procentuarische Ziffer der Männer $33 \mathrm{pCt}$, die der Frauen 2,7 pCt. beträgt.

Indem ich mir ein Eingehen auf die Arbeit von Rey 1885***) für eine spätere Gelegenheit vorbehalte $\dagger$ ) komme ich nunmehr zu zwei grösseren Arbeiten des Jahres 1888. - Die erste derselben, die von Siemerling $+\dagger$ ), welcher das grösste bisher verarbeitete Beobachtungsmaterial $\mathrm{zu}$ Grunde liegt, wird weiterhin bei Mittheilung meiner eigenen Statistik sehr viel herangezogen werden; die letztere von Kellner $+\dagger$ ) bezieht sich auf Pfleglinge der Anstalt zu Saarge-

*) Adam, Considérations sur quelques cas de paralysio générale obez la femme. Thèse Paris. (Nach Westphal in Virchow-Hirsch.)

**) E. Régis, La paralysie générale chez la femme 1882. Gaz. méd. de Paris No. 9. (Nach Fürstner in Virchow-Hirseh 1882.)

***) Rey, Note sur la paralysio générale chez la femme, de l'hysterie chez les femmes atteintes de paralysie générale. Ann. méd. psyeh. 1885.

†) Die bei Idanow (s. unten) erwähnte Arbeit von Colowitch habe ich nicht aufgefunden. Sie ist dort aufgeführt unter dem Titel: Colowitch, Etude clinique sur la paralysie générale chez la femme. Thèse 1882.

H) Siemerling, Statistisches und Klinisehes zar Lehre von der progressiven Paralyse der Frauen. Separat-Abdruck aus den Charité-Annalen. XIII. Jahrgang.

$++\dagger)$ Kellner, Beobachtungen über Dementia paralytica bei Frauen. Diss. Marburg. 1888. 
münd. - Das Verhältniss der Frauen- zu den Männerparalysen stellte sich danach wie 1:3,7. - Bei den Frauen erwiesen sich alkoholische und sexuelle Excesse besonders wirksam, hingegen das Klimacterium nur in geringem Masse. Der Verlauf der Krankheit war rubiger und länger hingezogen als bei den Männern. Sonst stimmte das klinische Bild bei beiden Geschlechtern im Wesentlichen überein, uur machte sich psychische Schwäche bei den Frauen früher und in stärkerem Grade bemerkbar.

Es schliesst sich hieran die Arbeit von Greppin*) aus dem Jahre 1890; derselben dienen die Krankengeschichten von 26 weiblichen Paralytischen zur Unterlage, welche in den Jahren 1876 bis 1888 in der Baseler Klinik Aufnabme fanden. Dabei stellt sich das Verhältniss der Frauen zu den Männern wie 1:4,5. Nur eine Kranke befand sich zur Zeit der Erkrankung noch unterhalb des 30. Lebensjahres (28 Jahre alt). Die grosse Mehrzahl der Erkrankungen fiel hingegen in das eigentliche klimacterische Alter (14 Fälle zwischen 45 und 52 Jahren). Die Verheiratheten and Verheirathetgewesenen überwogen bedeutend über die Ledigen. - Hinsichtlich der Krankheitsursachen meint Greppin in Uebereinstimmung mit einigen der früheren Autoren, das Klimacterium in den Vordergrund stellen za müssen; immer waren daneben aber noch andere Factoren verantwortlich zu machen, von denen besonders körperliche und geistige Ueberanstrengungen und die hereditäre Prädisposition von grosser allgemeiner Bedeutung waren. Hinsichtlich des Einflusses der Lues, welche nur 4 mal in den Antecedentien der Kranken nachweisbar war, misst Greppin selbst seiner Statistik keine entscheidende Bedeutung bei. Was die Symptomatologie und den Verlauf betrifft, so sei hier erwähnt, dass nur in 7 Fällen von vornherein das Bild der apathischen Demenz, in 11 bezw. 8 Fällen hingegen das einer mehr oder weniger ausgesprochenen Manie mit Grössenideen bezw. einer ängstlichen oder melancholisch-hypochondrischen Depression vorhanden war. - Von körperlichen Symptomen ist die Häufigkeit von Anomalien der Pupillenlichtreaction zu erwähnen (Verlust bezw. Trägheit doppelt- oder einseitig in 24 Fällen).

Die Patellarreflexe wurden $12 \mathrm{Mal}$ vermindert oder erloschen, 10 Mal erhöht gefunden.

Auf einige weitere Einzelheiten wird gelegentlich zurückgekommen werden.

*) Greppin, Ueber 26 Fällo von progressiver Paralyse bei Frauen. Zeitschr. für Psychiatrie Bd, 46. S, 553. 
Ueber die in der Bonner Anstalt hinsichtlich der progressiven Paralyse der Frauen gemachten Erfahrungen berichtet Berg*) im Jahre 1891 unter Zugrundelegung von 41 Fällen. - Das Verhältniss beider Geschlechter stellt sich hinsichtlich der Zahl der Erkrankungen wie $1: 5,4$. Bei Besprechung der Aetiologie wird hervorgehoben, dass ein Drittel der Kranken durch Trunksucht der Eltern belastet war. - Syphilis war sicher constatirt in 3, höchst wahrscheinlich in 2 Fällen, doch hält Berg selbst diese Zahlen für viel zu niedrig gegriffen, weil noch in vielen anderen Fällen der Verdacht einer Infection gerechtfertigt erschien. - Von Interesse ist die verhältnissmässig grosse Zahl (4) der Fälle, in denen bereits vor der Paralyse einmal eine Geistesstörung aufgetreten war.

In drei Fällen war ein sichtbarer Einfluss der Gravidität bezw. des Puerperiums zu constatiren; im Klimacterium befanden sich neun Kranke, aber nur bei einer derselben war das Klimacterium das einzige nachweisbare ätiologische Moment.

Fast die Hälfte der Fälle war 30-40 Jahre alt. Für die Berechnung der Dauer der Krankbeit konnten 30 Fälle verwerthet werden; dabei ergab sich keine Bestätigung der vielfach gehegten Annahme, dass der Verlauf der Paralyse bei Frauen im Allgemeinen wesentlich länger sei als bei Männern.

Aus neuester Zeit sind endlich noch zwei Arbeiten zu erwähnen, nämlich diejenige von A. Westphal ${ }^{* *}$ ), welche sich wiederum auf Kranke aus der psychiatrischen Klinik der Charité bezieht, und diejenige von Idanow*** ), dessen Fälle einem Moskauer Krankenhause angehören.

Der Westphal'sche Aufsatz wird weiter unten Berücksichtigung finden; ebenso wird auch auf die durch eine zusammenfassende Art der Darstellung und sorgfältiges Literaturstudium ausgezeichnete Arbeit Idanow's noch zurückzukommen sein; hier beschränke ich mich darauf, die Schlussfolgerungen desselben kurz zu resümiren, soweit dieselben für die späteren Darlegungen von Interesse sind.

1. Häufigkeit der Erkrankung bei beiden Geschlech tern. Eine Collectivberechnung für acht europäische Staaten (Däne-

*) Berg, Ueber die progressive Paralyse der Franen. Inaug.-Dissert. Bonn 1891.

**) A. Westphal, Aetiologisches und Symptomatologisches zur Lehre von der progressiven Paralyse der Frauen. 1893. Charité-Ann. XVIII.

***) ldanow, De la paralysie générale chez la femme. Annal. méd. psych. 1894. Mai Juni. 
mark, Oesterreich, Italien, Deutschland, Russland, England, Belgien, Frankreich) ergiebt unter im Ganzen 104,000 Geisteskranken zwischen weiblichen und männlichen Paralytischen ein Verhältniss von $1: 3,8$. Bei einer Einzelberechnung für jeden einzelnen Staat nehmen nur Belgien und Frankreich insofern eine Sonderstellung ein, als die Anzahl der paralytischen Frauen etwas grösser ist, die übrigen zeigen untereinander keine erheblichen Differenzen.

Die progressive Paralyse nimmt überhaupt, besonders aber bei den Frauen, an Häufigkeit zu.

2. Aetiologie. Die ätiologischen Momente sind bei beiden Geschlechtern principiell identisch. Es wirken aber immer drei von ihnen zugleich (la triple formule étiologique). In erster Reihe steht die für beide Geschlechter gleich bedeutsame Syphilis, dann folgen Excesse aller Art und die psychischen Ursachen, von denen die ersteren (besonders Excesse in Alkohol) bei den Männern, die letzteren (Kummer, Gram, la lutte pénible pour l'existence) bei den Frauen überwiegen. - Die Häufigkeit der Syphilis stellt sich für die Gesammtzahl der paralytischen Frauen berechnet auf 68 pCt.

3. Lebensalter, klinischer Verlauf. Das bevorzugte Alter ist bei beiden Geschlechtern dasjenige zwischen 30 und 40 Jahren. Hiernach erscheint die Bedentung des Klimacteriums sehr fragwürdig.

Abgesehen von kleinen Besonderheiten, welche bei den Frauen beobachtet werden können, ist das Krankheitsbild bei beiden Geschlechtern dasselbe, so dass die Abgrenzung einer "forme féminine“ nicht gerechtfertigt erscheint.

$\mathrm{Zu}$ den bisher angeführten Veröffentlichungen, welche ausschliesslich oder oder doch ganz vorzugsweise die Paralyse der Frauen behandeln, kommt nun noch eine sehr grosse Anzahl von Arbeiten mehr allgemeinen Inhalts, in denen vielfach entsprechende statistische und klinische Angaben auch über das weibliche Geschlecht enthalten sind. Da eine Berücksichtigung der gesammten umfangreichen Literatur weit über den Rahmen dieser Arbeit hinausgehen würde, sind aus derselben nur einige neuere Arbeiten herausgegriffen, welchen eine grössere Statistik zu Grunde liegt.

In Mendel's bekannter Monographie ist der "progressiven Paralyse beim weiblichen Geschlecht" ein besonderer Abschnitt gewidmet, in welchem die damals vorhandenen Statistiken der verschiedenen

*) Mendel, Die progressive Paralyse der Irren. Berlin 1880. 
Länder zusammengefasst werden. Mendel constatirte eine zweifellose Zunahme der weiblichen Paralysen, und zwar speciell in den jüngeren Lebensjahren.

Eickholt*) berichtet aus der Grafenberger Anstalt über ein Verhältniss der weiblichen zu den männlichen Paralytischen wie 1:6. Der erblichen Belastung konnte er keine bedeutende ätiologische Rolle zugestehen, noch weniger dem Klimacterium.

Die Arbeit von Reinhard**) verdient besondere Beachtung, weil sie auf dem grossen Material der Hamburger Anstalt aus den Jahren 1882 bis Anfang 1884 basirt, und durch eine besonders sorgfältige Statistik ausgezeichnet ist. Die letztere kommt besonders seinen Erörterungen über die ätiologische Bedeutung der Syphilis bei den Paralytischen zu Gute, welche durch Paralleluntersuchungen an einer grossen Anzahl nicht paralytischer Geisteskranker controlirt wird. Dabei rechnet Reinhard allerdings die Prostituirten sämmtlich zu den Syphilitischen, vorausgesetzt, dass dieselben mehrere Jahre beim Gewerbe waren, ebenso nimmt er alle Frauen, die mehr als einmal abortirt haben, als syphilitisch an, ein Verfahren, über das sich jedenfalls streiten lässt (s. unten bei Siemerling). Er kommt zu dem Resultat, dass von 226 Männern 16,7 pCt., von 85 Weibern 29,4 pCt. syphilitisch inficirt waren. Nach Abzug von 15 in die letztere Zahl mit einbegriffenen Prostituirten ergiebt sich nur für 14,2 pCt. der Weiber eine syphilitische Infection. - Das Ergebniss für sämmtliche hier in Betracht gezogene Paralytische (303) ist Syphilis in $28 \mathrm{pCt}$.

Von grossem Interesse sind dann Reinhard's Erörterungen über die Häufigkeit der Syphilis bei Tabesparalyse und bei gewöhnlicher Paralyse. Unter 87 paralytischen Weibern fand er die Symptome von Hinterstrangserkrankung in 29,1 pCt., bei den so complicirten Paralysen war Syphilis nachweisbar in 34,6 pCt., bei den gewöhulichen Paralysen hingegen nur in $26,2 \mathrm{pCt}$.

Das Verbältniss der paralytischen Weiber zu den Männern stellt sich durehschnittlich auf 1:3,2 und zeigt von Jahr zu Jahr keine erheblichen Schwankungen; dagegen ist für das letzte Decennium eine auffallende Zunahme der Paralyse im Verhältniss zu den anderen Gei-

*) Eickholt, Zur Kenntniss der Dementia paralytica. Allg. Zeitschrift für Psychiatrie Bd. 41.

**) Reinhard, Beitrag zur Aetiologie der allgemeinen progressiven Paralyse der Irren mit besonderer Berücksichtigung des Einflusses der Syphilis. Allg. Zeitschrift für Psychiatrie Bd. 41. 
sleskrankheiten zu verzeichnen. - Das Lebensalter der erkrankenden Weiber soll etwas höher sein als das der Männer.

Reinbard kommt zu dem Schlusse, dass die Syphilis zwar unter Umständen die Veranlassung zum Ausbruch der Paralyse sein kann, dass sie aber im Allgemeinen nur als eine der prädisponirenden Ursachen derselben angesehen werden darf; er ordnet die ätiologischen Momente so, dass in erster Linie der gesteigerte Kampf ums Dasein und die schädigenden Einfüsse des socialen Lebens, dann die Trunksucht (bei Männern), die Syphilis und endlich die Erblichkeit verantwortlich zu machen sind. - Daran sollen sich dann noch die anderen mannigfachen Einflüsse, nnter Anderem auch die Kopfverletzungen, schliessen. Hieraus ergeben sich die verschiedensten Möglichkeiten der Combination dieser verschiedenen Momente.

Ziehen*) hat zwischen paralytischen Weibern und Männern der Jenenser Anstalt ein Verhältniss wie 1:7,7 gefunden. - Das Durchschnittsalter der Frauen bei der Aufnahme betrug 45 Jahre.

Zur Feststellung der Sypbilis empfieblt Ziehen die Ermittelung zweier verschiedener Zahlen, von denen die eine alle nur irgendwie verdächtigen Fälle (also z. B. auch Aborte der Frau, weiche Schanker) enthält, während bei der zweiten nur diejenigen Fälle mitgerechnet sind, in denen mehrere dringend verdächtige Momente. zusammentreffen. So ergiebt sich eine zu grosse und eine zu kleine Ziffer, für die paralytischen Fraven 30 und 46 pCt., zwischen welchen beiden Zablen also die dem thatsächlichen syphilitischen Procentsatz der weiblichen Paralytischen ungefähr entsprechende Zahl läge.

Ziehen schliesst aus seinen Berechnungen, dass die Paralyse fast stets die Folge mehrerer Ursachen ist, und dass die Syphilis dabei nicht einmal die erste Rolle spielt, sondern von der erblichen Anlage übertroffen wird. „Die Erblichkeit disponirt zu Geisteskrankheiten überhaupt, die Syphilis speciell zur Paralyse".

Die Statistik von Kaes"*) bezieht sich auf 9148 Geisteskranke, die in Hamburg-Friedrichsberg von 1870-1889 aufgenommen wurden, sie soll die oben erwähnte Reinhard'sche Arbeit also gewissermassen ergänzen. Unter diesen Kranken befanden sich 1093 Männer,

*) Ziehen, Beitrag zar Frage des Zusammenhanges zwischen progressiver Paralyse und Syphilis. Neurol. Centralbl. 1887. S. 198.

**) Kaes, Beiträge zur Aetiologie der allgemeinen Paralyse nebst einleitenden, allgemein statistischen Bemerknngen. Allg. Zeitschrift für Psychiatrie Bd. 49. S. $614 \mathrm{ff}$. 
319 Frauen mit Paralyse. - Das Verhältniss zwischen beiden Geschlechtern stellt sich demnach auf $1: 3,4$ (Reinhard s. oben $1: 3,2$ ).

Die Frage, ob die Paralyse im Allgemeinen in den letzten 20 Jahren zugenommen hat, verneint er, da er vielmehr von 1880 bis 1881 an einen langsamen Abfall der Paralysenzugänge constatiren konnte.

Was das Lebensalter der paralytischen Frauen betrifft, so liegt das Maximum der Erkrankungen zwischen dem 40. und 45. Lebensjahre; zwischen dem 26. und 29. Jahre ist die absolute Zahl der paralytischen Frauen deshalb grösser als die der Männer, weil sich hier viele Prostituirte finden. - Für die Frauen soll ferner charakteristisch sein, dass sich eine neue Erhebung der Erkrankungsziffer zwischen dem 55. und 60. Lebensjahre findet.

Unverhältnissmässig gross fand $\mathrm{K}$ aes die Zahl der kinderlosen Ehen (fast ein Drittel aller Ehen).

Aus neuester Zeit liegt dann noch eine Arbeit von Hougberg*) vor, welche über alle von $1875-1892$ in der Irrenanstalt Lappwick bei Helsingfors aufgenommenen Paralytischen berichtet (98 Männer und 9 Frauen). Das Verbältniss stellt sich demnach für die Frauen auffallend günstig (wie 1:11). - Die Anzahl derselben ist zu klein, um weitere Schlüsse zu gestatten. Erwähnenswerth ist noch die von $\mathrm{Hougberg}$ in Uebereinstimmung mit den anderen nordischen Autoren constatirte Häufigkeit der Syphilis (in 75,7 bis 86,9 pCt. aller Fälle),

Im Gegensatz hierzu fand Lojacono**) für einen Zeitraum von 5 Jahren bei den männlichen Paralytischen nur in 10,2 pCt., bei den weiblichen gar keine Syphilis. Nach ihm stehen unter den ätiologischen Momenten obenan: ungünstige sociale Verhältnisse, es folgen hereditäre Prädisposition, Syphilis (nur bei den Männern) und traumatische Einflüsse, dann die anderen Ursachen. - Verhältniss der Frauen zu den Männern wie $1: 11$.

Endlich werde ich im Folgenden mehrfach Gelegenheit nehmen müssen, auf die Arbeiten von Áscher**) und Oebekef) zu ver-

*) Hougberg, Beiträge zur Kenntniss der Aetiologie der progressiven Paralyse mit besonderer Berücksichtigung der Syphilis. Allg. Zeitschrift für Psychiatrie Bd. 50.

**) Lojacono, La Paralisi generale progressiva in Sicilia Napoli 1894.

***) A scher, Beitrag zur Kenntniss des Verlaufs und der Aotiologie der allgemeinen Paralyse. Allg. Zeitschrift für Psychiatrie Bd. 46.

†) $\mathrm{O}_{\theta} \mathrm{bek} \theta$, Zur Aetiologie der allgemeinen fortschreitenden Paralyse. Allg. Zeitschrift für Psychiatrie Bd. 49. 
weisen, die sich zwar nur auf männliche Paralytische (aus Dalldorf bezw. Endenich) beziehen, aber sonst eine Reihe allgemein interessanter Angaben enthalten.

\section{Figene Statistik.}

Die nachstehende Zusammenstellung bezieht sich auf 256 Fälle von. Paralyse, welche in den Jahren von 1887 bis Mitte 1891 auf der Frauenabtheilung der Berliner psychiatrischen Klinik behandelt wurden. Diese Zahl repräsentirt nicht sämmtliche Paralysen, welche innerbalb dieses Zeitraumes aufgenommen wurden, sondern nur diejenigen, in welchen durch eine hinreichend lange Beobachtung die Diagnose gesichert war.

Die Arbeit schliesst sich demnach zeitlich direct an die bereits erwähnte von Siemerling an, in welcher dieser über 353 von 1877 bis 1886 anf derselben Abtheilung beobachtete Paralysen berichtet hat. Auch inhaltlich soll sie eine Fortsetzung der vorgenannten Arbeit bilden, indem möglichst dieselben Gesichtspunkte festgehalten und die dort erörterten Fragen weiter verfolgt sind. Obwohl neue Resultate hierbei kaum erwartet werden durften, so erschien doch die Zusammenfassung eines so grossen Beobachtungsmaterials in mancher Hinsicht lohnend. Das letztere wird, so weit ätiologische und symptomatologische Momente in Frage kommen, noch vergrössert durch die im vorigen Jahre erschienene, gleichfalls oben schon angefübrte Arbeit von A. Westphal, welcher 148 in der Zeit von Mitte 1891 bis 1893 beobachtete Fälle zu Grunde gelegt sind. So kommen wir auf die Gesammtziffer von rund 750 bezw. 600 Fällen, welche in einem Zeitraum von 16 bezw. 14 Jahren von verschiedenen Beobachtern, aber doch von einem einheitlichen Standpunkt aus untersucht und beobachtet worden sind, wobei es gewiss nicht ohne Werth ist, dass Jeder von uns Dreien im Wesentlichen nur über selbstbeobachtete Fälle berichtet hat. - Die Einheitlichkeit der Beobachtung kommt besonders auch den Augenbefunden zu gute, welche mit wenigen Ausnahmen einer specialärztlichen Controle und zwar bis 1890 durch Herrn Prof. Uhth off, später durch Herrn Privatdocenten Dr. Hess und Herrn Dr. Ahlbrandt unterworfen worden sind.

Ich beginne zunächst mit einer Uebersicht der Krankenbewegung, welcher die von Mehlhausen in den Charité-Annalen gegebenen Zablen zu Grunde gelegt sind. Ich bemerke hierzu, dass die Abkürzungen G., K. und D. sich auf die in der Charité übliche Eintheilung in Geisteskranke, Krampfkranke und Deliranten beziehen, ferner dass 
die unverbältnissmässige Höhe der für das Jabr 1887 angegebenen Zahlen darin ihre Erklärung findet, dass in diesem Jahre das Berichtsjahr mit dem Etatsjahr in Uebereinstimmung gebracht werden musste, und demgemäss über 15 Monate berichtet ist. Die weiteren Zablen beziehen sich dann immer auf das Etatsjahr. - Um aber auch für das Jahr 1887 die Aufnahmeziffer von zwölf Monaten zu Grunde legen zu können, habe ich die Zahlen benutzt, welche Siemerling für das Jahr 1887 in einer Anmerkung angiebt.

Tabelle I.

\begin{tabular}{|c|c|c|c|c|c|c|c|}
\hline Jahr & G. & $\mathrm{K}$. & D. & $\begin{array}{c}\text { Gesammt- } \\
\text { Summe. }\end{array}$ & $\begin{array}{c}\text { Zahl } \\
\text { der } \\
\text { Paralysen. }\end{array}$ & $\begin{array}{c}\text { Procent- } \\
\text { verhältniss } \\
\text { der } \\
\text { Paralysen } \\
\text { zur Ge- } \\
\text { sammtzahi }\end{array}$ & $\begin{array}{l}\text { Procent- } \\
\text { verhältniss } \\
\text { der } \\
\text { Paralysen } \\
\text { zu G. }\end{array}$ \\
\hline 1880 & 324 & 92 & 56 & 472 & 29 & 6,1 & 8,9 \\
\hline 1881 & 392 & 132 & 44 & 568 & 44 & 7,7 & 11,2 \\
\hline 1882 & 380 & 137 & 38 & 555 & 61 & 10,9 & 16,0 \\
\hline 1883 & 412 & 117 & 44 & 578 & 65 & 11,3 & 15,8 \\
\hline 1884 & 436 & 141 & 41 & 618 & 66 & 10,6 & 15,1 \\
\hline 1885 & 469 & 176 & 53 & 698 & 56 & 8,0 & 11,9 \\
\hline 1886 & 505 & 158 & 53 & 716 & 46 & 6,4 & 9,1 \\
\hline $1887 / 88$ & 670 & 261 & 107 & 1038 & 87 & 8,3 & 12,0 \\
\hline $188 / / 80$ & $(477)$ & (185) & (85) & $(747)$ & (49) & $(6,3)$ & $(10,2)$ \\
\hline $1888 / 89$ & 553 & 249 & 74 & 876 & 68 & 7,7 & 12,1 \\
\hline $1889 / 90$ & 579 & 395 & 72 & 986 & 95 & 9,6 & 16,3 \\
\hline $1890 / 91$ & 544 & 307 & 65 & 916 & 120 & 13,1 & 22,0 \\
\hline $1891 / 92$ & 562 & 309 & 112 & 983 & 112 & 11,3 & 19,9 \\
\hline
\end{tabular}

Es ergiebt sich hieraus, dass das von Siemerling für die Jahre 1884, 1885, 1886 constatirte Abfallen des Procentverbältnisses der Paralytischen zu den übrigen weiblichen Geisteskranken von 1887 ab nicht weiter verfolgbar ist, sondern dass vielmehr ein unregelmässiges aber stetiges Ansteigen der Zahl von Jahr zu Jahr und nur für 1891 ein Wiederabsinken stattfindet. Ueber das Verhalten der beiden Geschlechter in dieser Hinsicht giebt Tabelle III. genauere Auskunft. Wenn nun hierbei auch mit der Möglichkeit einiger diagnostischer Irrthümer gerechnet werden muss, so könnte es sich da nur um wenige Fälle bandeln, durch deren Ausscheidung das Gesammtresultat nicht wesentlich beeinflusst werden würde.

Der Versuch, die procentuarischen Differenzen der Aufnahmeziffern für weibliche Geisteskranke überhaupt und speciell für Paralyse mit der Zunahme der weiblichen Bevölkerung Berlins in Parallele zu 
setzen, gelingt deshalb nur unvollkommen, wie das übrigens auch von Siemerling hervorgehoben wird, weil die Vergleichsobjecte zu ungleichartig und insbesondere bei der Bevölkerungszunahme eine Anzahl von Elementen mit einbegriffen sind, welche nach ihrem Lebensalter (Kinder, Greisinnen) oder nach ihrer Lebensstellung (Frauen der höberen Stände) für die Erwerbung einer Paralyse gar nicht oder in äusserst geringem Masse geeignet sind, und andererseits unter den Aufnahmen nur eine relativ geringe Rolle spielen.

Hingegen lässt sich aus einer Differenz zwischen dem procentuarischen Zuwachs an Geisteskranken und demjenigen an Paralysen immerhin ein Schluss ziehen, vorausgesetzt, dass dieselbe gross genug: ist, um gewisse Zufälligkeiten (grössere Aufnahmebedürftigkeit der Paralysen, frühere Einweisung in die Anstalt in Folge besserer Diagnose der Krankheit) auszuschliessen.

Nach den in Bezug auf die vorstehenden Punkte ron Siemerling angestellten Berechnungen ergab sich für die Jahre 1880-1885 eine jährliche Zunahme der weiblichen Bevölkerung um 3,6 pCt., während die Zunahme der Geisteskranken pro Jahr 9 pCt. und diejenige der Paralysen 11,6 pCt. betrug. Diese Differenz von 20 pCt. ist zu unerheblich, um daraus eine Zunahme der weiblichen Paralyse zu folgern. Siemerling kommt sogar auf Grund seiner procentuarischen Vergleichstabelle, die unten mit abgedruckt ist, zu dem entgegengesetzten Schlusse, dass nämlich die Paralyse unter der mittleren und unteren weiblichen Bevölkerung Berlins abgenommen babe, während Thomsen bei den Männern in dem gleichen Zeitraum eine Zunahme der Krankheit constatiren konnte.

Auf Grund meiner, nach denselben Gesichtspunkten aufgestellten Statistik komme ich hinsichtlich meiner Fälle zu einem abweichenden Resultate. Ich fand einen jährlichen Zuwachs der Gesammtaufaufnahme von 8 pCt. (10 pCt. Siemerling), der Geisteskranken von nur 5 pCt. ( 9 pCt. Siemerling) und einen solchen der Paralysen von 13,9 pCt. (11,6 pCt. Siemerling). Die Zunahme der weiblichen Bevölkerung betrug pro Jahr ca. 4 pCt. ( $3^{3} / s$ pCt. Siemerling). Die Zahlen der einzelnen Jahre sind aus der nebenstehenden Tabelle II. ersichtlich, welche mit der von Siemerling gegebenen Tabelle II. verschmolzen ist.

Wir sehen also, dass der procentuarische Zuwachs der Geisteskranken sich ziemlich gleich bleibt, jedenfalls keine erheblicben Schwankungen aufweist, während bei den Paralytischen, abgesehen von den letzten angeführten Jahren, die unverkennbare Tendenz zum Ansteigen vorhanden ist. 
Die Differenz zwischen dem procentuarischen jährlichen Zuwachs der Geisteskranken und dem der Paralytischen erscheint mit 5 gegen 13,9 auffallend gross und würde sich nach Berichtigung etwaiger diagnostischer Irrthümer vielleicht etwas niedriger stellen; immerhin bleibt sie aber auch dann noch gross genug, um den Schluss zu rechtfertigen, dass die von Siemerling für die Jahre 1880-1886 festgestellte Abnahme der Paralyse der Frauen in Berlin weiterhin wiederum einer Zunahme gewichen ist.

\begin{tabular}{|c|c|c|}
\hline Jahr. & $\begin{array}{c}\text { Geisteskranke. } \\
\text { Procent. }\end{array}$ & $\begin{array}{c}\text { Paralytiker. } \\
\text { Procent. }\end{array}$ \\
\hline $\begin{array}{l}1880 / 81 \\
1881 / 82 \\
1882 / 83 \\
1883 / 84 \\
1884 / 85 \\
1885 / 86 \\
1886 / 87 \\
1887 / 88 \\
1888 / 89 \\
1889 / 90 \\
1890 / 91 \\
1891 / 92\end{array}$ & $\begin{array}{l}+20 \\
-3 \\
+\quad 8 \\
+\quad 5 \\
+\quad 7 \\
+\quad 7 \\
-5 \\
-\quad 5,5 \\
+13,7 \\
+\quad 5 \\
+\quad 6 \\
+\quad 3\end{array}$ & $\begin{array}{r}+50 \\
+38 \\
+\quad 6 \\
+\quad 1 \\
+17 \\
-20 \\
+6 \\
+6,5 \\
+38 \\
+40 \\
+26 \\
-7\end{array}$ \\
\hline
\end{tabular}

Aus der letzten Columne der Tabelle III. ist ersichtlich, dass das Verhältniss der Häufigkeit der paralytischen Erkrankung bei beiden Geschlechtern für jedes einzelne Jahr nicht unerhebliche Schwankungen, zwischen 2,8:1 und 4,4:1, zeigt; eine Erklärung hierfür zu geben, bin ich ausser Stande. Hingegen ergiebt sich für den gesammten Zeitraum von 1887 bis 1892 ein Verhältniss der Betheiligung, welches fast genau mit den von Siemerling gefundenen Ziffern übereinstimmt und deshalb wohl als ein definitives angesehen werden kann. Dasselbe liegt $z$ wischen $1: 3,6$ und $1: 3,4$, lässt sich also auf $1: 3,5$ berechnen.

Um über das Alter meiner Kranken Klarheit zu gewinnen, habe ich zunächst eine Anzahl von Fällen nach dem Alter zur Zeit der Aufnahme zusammengestellt und dieselben mit der von Siemerling gegebenen Tabelle III. vereinigt (s. Tabelle IV.). - In einigen späteren Tabellen ist das Alter zur Zeit des Todes als Grundlage gewählt; dieses jedenfalls zweckmässigere Verfahren konnte aber bei unseren Fällen aus verschiedenen Gründen nicht durchgeführt 
Tabelle III.

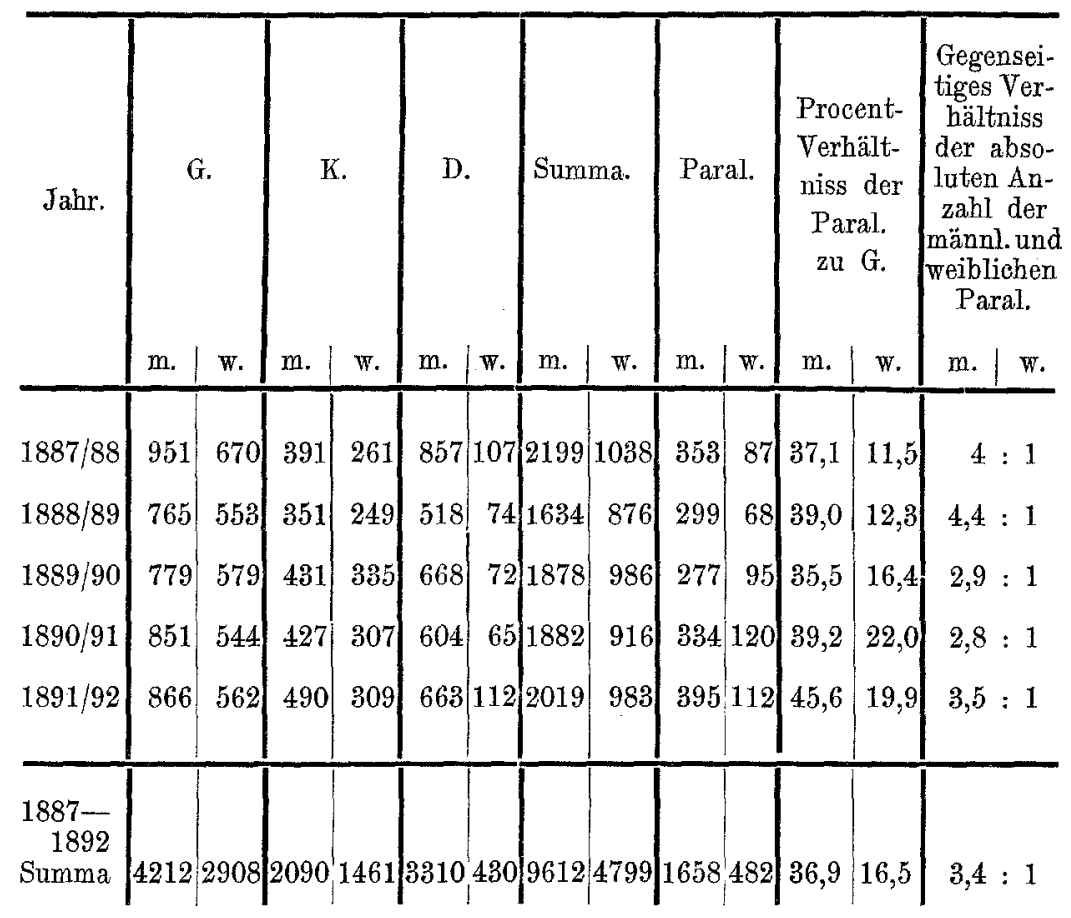

werden. Die betreffenden Tabellen gewähren die Möglichkeit, weiterhin hinsichtlich einiger Punkte erwünschte Vergleiche mit den männlichen Paralytikern Ascher's zu ziehen, welcher fast überall das Alter zur Zeit des Todes zu Grunde gelegt hat. - Endlich habe ich in einer meiner Tabellen wiederum ein anderes Princip gewählt, indem ich an eine der Siemerling'schen anknüpfend für eine Anzahl der Fälle das Alter zur Zeit des Ausbruches der Paralyse ausrechnete und zum Ausgangspunkt nahm.

Es zeigt sich nun, dass dem Lebensalter von 36-40 Jahren, welches Siemerling als das am meisten bevorzugte fand, auch weiterhin die meisten Fälle angehören. Ich fand in dieser Altersklasse 67 unter 254 Fällen $=26,3$ pCt. (Siemerling 98 unter $353=27,7$ pCt.). Die Gesammtsumme von 607 Fällen ist mit $165=27,1$ pCt. betheiligt.

Ich habe sodann die Frage weiter verfolgt, ob die paralytischen 
Statistisches und Klinisohes zur Kenntniss d. paralyt. Geistesstörung.

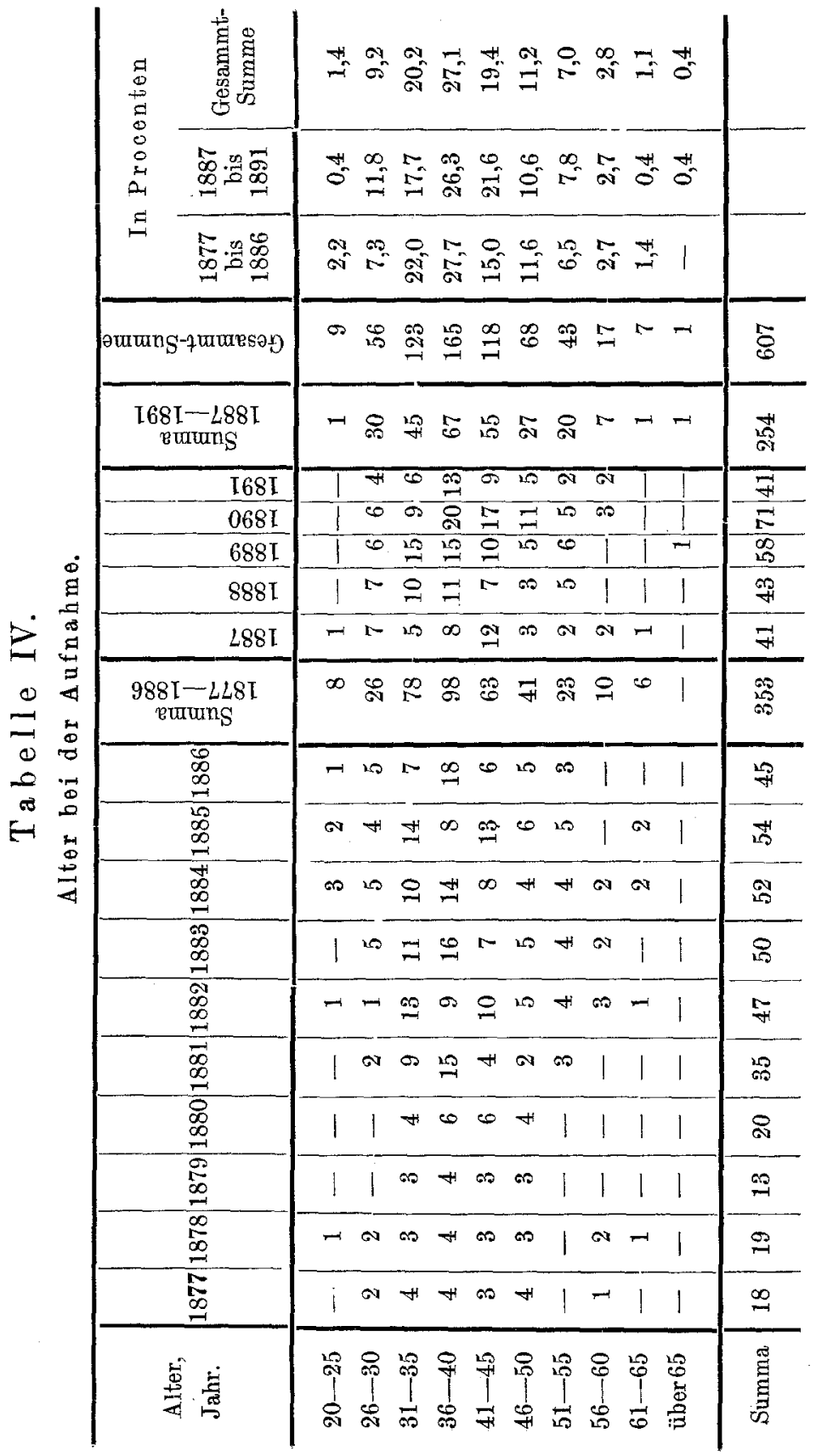


Weiber in den letzten Jahren in einem jüngeren Alter zur Aufnahme kommen als früher.

Siemerling konnte dieselbe auf Grund eines Vergleiches zwischen einer Anzahl von Paralysen der Jahre 1877-1881 einerseits und $1882-1886$ andererseits bejahen.

Ich stelle in derselben Weise die Jahre 1882-1886 und 1887 bis 1891 neben einander, indem ich die Siemerling'schen Zahlen aus 1877-1881 in Parenthese davorsetze.

Ta b e 11 e V.

Alter bei der Aufnabme.

A. von 105 Paral. aus 1877-1881 incl.

B. von 248 Paral. aus $1882-1886$ incl.

C. von 254 Paral. aus $1887-1891$

in Procenten:

\begin{tabular}{|c|c|c|c|c|c|c|c|c|c|}
\hline & & & & Alte. & , Ja & hre: & & & \\
\hline & $\stackrel{9}{\circ}$ & $\prod_{0}^{\infty}$ & $\frac{19}{60}$ & 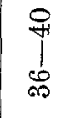 & $\stackrel{19}{7}$ & $\sum_{0}^{0}$ & $\frac{1}{10}$ & $\prod_{0}^{8}$ & $\int_{0}^{0}$ \\
\hline $\begin{array}{l}\text { A. } \\
\text { B. } \\
\text { C. }\end{array}$ & $\begin{array}{l}0,95 \\
2,8 \\
0,3\end{array}$ & $\begin{array}{r}5,6 \\
8,0 \\
11,8\end{array}$ & $\begin{array}{l}21,9 \\
22,1 \\
17,7\end{array}$ & $\begin{array}{l}39,0 \\
21,3 \\
26,3\end{array}$ & $\begin{array}{l}18,0 \\
17,7 \\
21,2\end{array}$ & $\begin{array}{l}15,2 \\
10,0 \\
10,2\end{array}$ & $\begin{array}{l}2,8 \\
8,0 \\
7,8\end{array}$ & $\begin{array}{l}2,8 \\
2,8 \\
2,7\end{array}$ & $\begin{array}{l}0,95) \\
2,0 \\
0,3\end{array}$ \\
\hline m Mittel & 1,4 & 9,2 & 20,2 & 27,1 & 19,4 & 11,2 & 7,0 & 2,8 & 1,1 \\
\hline
\end{tabular}

Dabei zeigen sich innerhalb der einzelnen Columnen nicht unerhebliche Schwankungen, doch ist eine gleichmässige Zunahme der im Alter von 26-30 Jahren stehenden Paralysen zu erkennen. Einen besseren Ueberblick erhalten wir, wenn wir grössere Zeitabschnitte als von $5 \mathrm{zu} 5$ Jahren betrachten, in der Weise, wie Ascher dies für die Männer gethan hat. Dieser Autor unterscheidet ein frühes Mannesalter rom 20.-35. Jahre, ein mittleres vom 35.-50. Jahre und endlich ein späteres Mannesalter, welches die letzten Altersklassen umschliesst.

In entsprechender Weise unterscheide ich bei den Frauen ein jugendliches Alter vom 20.-30. Jahre, ein reifes Frauenalter vom 30.-45. Jahre, endlich ein spätes Frauenalter vom 45. Jahre aufwärts - hierbei ist das 45 . Lebensjahr als dem Beginn des eigentlichen Klimacteriums entsprechend angenommen. 
Es ergiebt sich dann:

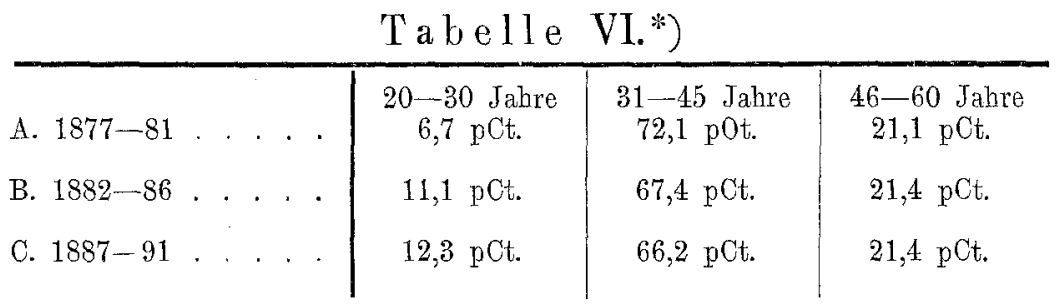

Während also die Betheiligung der höchsten Altersklasse nur unerhebliche Schwankungen zwischen 21,1 und 21,4 zeigt, ergiebt sich für das reife Franenalter eine zunächst sehr erhebliche, dann geringere Abnahme, für das jugendliche Alter aber eine zunächst sehr bedeutende, später immerhin noch bemerkenswerthe Zunahme der procentuarischen Betheiligung.

Hiernach kann ich auf Grund meiner Erfahrung der Siemerling'schen Schlussfolgerung, dass die paralytischen Frauen jetzt in einem jüngeren Lebensalter zur Aufnahme kommen als früher, nur beipflichten, obschon die Zunahme der jugendlichen Paralysen in den letzten vier Jahren keine so auffallende war, wie in der vorhergehenden Beobachtungsperiode.

Aus dieser früher eintretenden Aufnahmebedürftigkeit der paralytischen Weiber darf man nun nicht ohne Weiteres folgern, dass auch der Beginn der Erkrankung jetzt in ein jüngeres Lebensalter fällt, wie in der früheren Zeit. Denn jene liesse sich $z$ wangslos auch so erklären, dass die Entwickelung der Krankheit jetzt eine rapidere ist und in Folge dessen der Anstaltsaufenthalt früher nothwendig wird.

Um hierüber in's Klare zu kommen, bin auch ich bemüht gewesèn, das Alter zur Zeit des Krankheitsausbruches festzustellen. Es bedarf kaum eines Hinweises darauf, mit welchen Schwierigkeiten hierbei zu rechnen ist. Man mag den Zeitpunkt zu erforschen suchen, wo die Angehörigen selber merkten, dass es mit den Patienten, „nicht mehr ganz in Ordnung war", wie Ascher dies versucht hat, oder man mag mit Siemerling und mir festzustellen bestrebt sein, wann gewisse sichere Frübsymptome zuerst aufgetreten sind, immer ist man mehr oder weniger von den Angaben der Angehörigen abhängig; deren Werth leider oft ein recht fragwürdiger ist.

*) Die Fälle, in denen die Altersgrenze von 60 Jahren überschritten war, sind hier nicht mitgerechnet, weil gerade diese Fälle zum Theil diagnostisch unsicher sind. 
Die folgende, über die Dauer der Krankheit vor der Aufnahme Auskunft gebende Tabelle bezieht sich auf 172 Fälle, in denen sich die Krankheit mit einiger Sicherheit bis zu einem bestimmten Zeitpunkt verfolgen liess; dabei sind die Angaben der Kranken selbst nur insofern berücksichtigt worden, als sie durch diejenigen von Angehörigen ergänzt und bestätigt wurden.

Tabelle VII.

\begin{tabular}{|c|c|c|c|c|c|c|c|c|c|c|c|c|c|c|}
\hline \multirow[b]{2}{*}{$\begin{array}{l}\text { Jahr- } \\
\text { gang. }\end{array}$} & \multicolumn{13}{|c|}{ Krankheitsdauer vor der Aufnahme: } & \multirow[b]{2}{*}{ 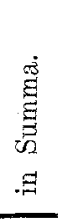 } \\
\hline & $\stackrel{0}{\infty}$ & 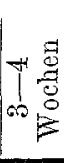 & 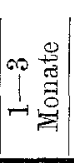 & 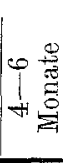 & 20 & $\mid \frac{T}{9}$ & $\left.\right|_{-1} ^{+}=$ & $\sum_{-\rightarrow \infty}^{\infty}$ & $\left.\right|_{\infty} ^{\infty}$ & 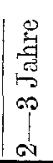 & 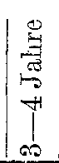 & 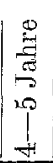 & 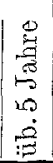 & \\
\hline 1887 & 2 & 1 & 4 & 4 & 1 & 9 & - & 1 & 5 & 1 & - & - & - & 28 \\
\hline 1888 & 3 & 4 & 4 & 5 & 3 & 4 & 1 & - & 1 & 2 & 1 & $\ldots$ & - & 28 \\
\hline 1889 & - & 1 & 4 & 7 & 6 & 4 & - & 2 & 1 & 2 & 3 & 2 & 1 & 33 \\
\hline 1890 & 4 & 3 & 9 & 4 & 8 & 5 & - & 7 & 3 & 4 & 1 & 2 & 4 & 54 \\
\hline 1891 & 2 & 2 & 5 & 5 & 1 & 5 & - & 2 & 3 & 1 & 3 & - & - & 29 \\
\hline Summa & 11 & 11 & 26 & 25 & 19 & 27 & 1 & 12 & 13 & 10 & 8 & 4 & 5 & 172 \\
\hline pCt. & 6,4 & 6,4 & 15,2 & 14,5 & 11,0 & 15,7 & 0,6 & 7,0 & 7,6 & 5,8 & 4,7 & 2,3 & 2,9 & \\
\hline
\end{tabular}

Die Betrachtung dieser Tabelle lässt ohne Weiteres erkennen, dass die Dauer der Krankheit vor der Aufnahme verhältnissmässig selten mehr als ein Jahr betragen hat. Unter den 172 Fällen, welche verwerthet werden konnten, finden sich 119, also 69 pCt., in den ersten 6 Columnen ( 1 Woche bis $1 \mathrm{Jahr}$ ) verzeichnet, und unter diesen sind wiederum 53 pCt., in denen die Krankheit nicht länger als 6 Monate bestanden hatte, als die Aufnahme nothwendig wurde. Diese Zahlen bleiben hinter den von Siemerling gefundenen noch etwas zurück $(75,5$ und $59 \mathrm{pCt}$.$) . Da hiernach nicht behauptet wer-$ den kann, dass die Aufnahmebedürftigkeit in der Zeit meiner Beob. achtung früher eingetreten wäre, als in den Vorjahren, so bleibt zur Erklärung der steigenden Aufnahmeziffer jüngerer Individuen nur die Annahme übrig, dass die Krankheit thatsächlich früber ausgebrochen ist. Dies suche ich durch Aufstellung einer weiteren Tabelle nachzuweisen, in welcher das mit einiger Sicherheit bekannte Alter zur Zeit des Ausbruches der Erkrankung zu Grunde gelegt ist. Es sind dies 165 Fälle, welche ich Siemerling's 120 Fällen gegenüberstelle. Ausserdem sind aus der Arbeit des Letzteren die Zahlen für 1877-1881 entnommen und wiederum in Klammern vorangesetzt. 


\section{Tabelle VIII.}

Es hatten das Alter bei dem Ausbruch der Erkrankung:
(A. von 34 Paralysen aus $1877-1881$ incl.)
B. von 120
"1882-1886 incl.
C. von 165
$1887-1890$ incl.

\begin{tabular}{|c|c|c|c|c|c|c|c|c|}
\hline Alter. & $20--25$ & $26--30$ & $31-35$ & $36--40$ & $41-45$ & $46-50$ & $51-55$ & $55-60$ Jahre \\
\hline (A. & - & 3 & 41 & 17 & 20 & 8 & 3 & 5) \\
\hline B. & 2 & 15 & 21 & 29 & 13 & 10 & 4 & 1 \\
\hline C. & 2 & 17 & 19 & 28 & 14 & 9 & 9 & 1 \\
\hline
\end{tabular}

Der Vergleich der Reihen B. und C. zeigt einen Zuwachs für das 26. bis 30. Lebensjahr, welchem in den beiden folgenden Columnen eine geringe Abnahme entspricht. In den übrigen Reihen finden geringe, sich zum Theil ansgleichende Schwankungen statt, nur für das 51. bis 55. Lebensjahr ergiebt sich wiederum ein sehr erheblicher Zuwachs.

Es fällt ferner auf, dass mit Bezug auf die Betheiligung des 26. bis 30. Lebensjahres die Reihe B. gegenüber der Reihe A. einen viel grösseren Zuwachs zeigt als die Reihe $\mathrm{C}$. gegenüber der Reihe B. Hierbei ist aber zu bedenken, dass der Reihe A. nur $34 \mathrm{Fälle} \mathrm{zu} \mathrm{Grunde} \mathrm{liegen,}$ und dass eine so kleine Zahl gegenüber den zablreichen Fehlerquellen eine viel geringere Sicherheit bietet als eine grössere; hätte auch aus den Jahren 1877 bis 1881 ein grösseres Material zur Verfügung gestanden, so wäre wahrscheinlich die Differenz keine so grosse geworden. - Die Sachlage wird wiederum deutlicher, wenn wir grössere Zeitabschnitte in der vorhin angegebenen Weise zusammenfassend betrachten.

Es zeigt sich dann Folgendes:

\begin{tabular}{l|c|c|c} 
& 20-30 Jahre. & $31-45$ Jahre. & $46-60$ Jahre. \\
\hline & 3 & 78 & 16 \\
A. & 17 & 63 & 15 \\
B. & 19 & 61 & 19
\end{tabular}

Hier fällt allerdings auf, dass die Anzahl der zur Zeit der Erkrankung bereits in einem höheren Alter stehenden Individuen (zwischen 46 und 60 Jahren) in der letzten Beobachtungsperiode eine viel grössere ist als in der vorletzten, und dass ihr Zuwachs den der jugendlichen Paralysen sogar erheblich übertrifft. Dies würde also 
lehren, dass die im mittleren Lebensalter stehenden Frauen jetzt im Verhältniss zu den Jüngsten und Aeltesten seltener erkranken. Man kann hieraus vielleicht schliessen, dass sich allmälig für Berlin ein Verhalten herausbildet, welches dem von Kaes*) für Hamburg beobachteten entspricht: nämlich ein Wiederansteigen der Erkrankungsziffer im höheren Lebensalter. Allerdings würde dies bei meinen Fällen in die erste Hälfte des 6. Lebensdecenniums, nicht wie bei Kaes in die zweite Hälfte fallen. Es wird bei späteren Statistiken darauf zu achten sein, ob eine solche Entlastung des mittleren Lebensalters zu Ungunsten des niedrigsten und höchsten thatsächlich auch weiterhin für Berlin zu constatiren und nicht lediglich eine vorübergehende Erscheinung ist. Ich glaube diese Frage auf Grund meiner Zahlen noch nicht ohne Weiteres beantworten zu können; denn gerade die hier in Frage kommenden Paralysen der höheren und höchsten Altersstufen bereiten der Diagnose die grössten Schwierigkeiten und lassen sich oft insbesondere gegen Altersveränderungen, nicht sicher abgrenzen. Bei der verhältnissmässig kleinen Zahl der hierher gehörigen Fälle spielen aber Irrthümer eine viel grössere Rolle. Ich lege deshalb auf den Zuwachs innerhalb der höchsten Altersstufe trotz seiner Erheblichkeit einen weit geringeren Werth als auf denjenigen innerhalb der niedrigsten, und glaube demnach, ein stetiges Anwachsen der Zahl der in relativ jüngeren Jahren Erkrankenden constatiren zu können.

Das durchschnittliche Alter berechnet sich für sämmtliche Fälle nach den einzelnen Jahren folgendermassen:

$$
\text { Tabelle IX. }
$$

\begin{tabular}{c|c}
\hline Jahr. & $\begin{array}{c}\text { Alter } \\
\text { im Durchschnitt. }\end{array}$ \\
\hline & \\
1887 & 40,0 Jahre \\
1888 & $39,0 \%$ \\
1889 & $39,3 \%$ \\
1890 & $41,8 \%$ \\
1891 & $39,7 "$
\end{tabular}

Die jüngste meiner Kranken war 21, die älteste 66 Jahre alt.

Den Civilstand habe ich für $124 \mathrm{Fälle}$ berechnet, welche bis zum Tode in Beobachtung gewesen waren*).

*) 1. c. S. 623.

**) Die Altersangaben sind hier aus änsseren Gründen mit Bezug auf dio 
Statistisches und Klinisches zur Kenntniss d. paralyt. Geistesstörung. 495

Die Tabelle X. zeigt, dass die Anzahl der Verheiratheten fast überall und mit zunehmendem Alter immer mehr überwiegt. Dies geht noch deutlicher aus der untenstehenden zusammenfassenden Aufstellung (Tabelle XI.) hervor.

Tabelle X.

\begin{tabular}{|c|c|c|c|c|c|c|c|c|c|c|c|}
\hline $\begin{array}{l}\text { Alter zur Zeit } \\
\text { des Todes. }\end{array}$ & 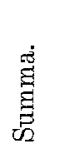 & \multicolumn{2}{|c|}{ ledig } & \multicolumn{2}{|c|}{$\begin{array}{l}\text { verehe- } \\
\text { licht }\end{array}$} & \multicolumn{2}{|c|}{$\begin{array}{c}\text { ge- } \\
\text { schieden }\end{array}$} & verlassen & ssen & $\begin{array}{c}\text { ver- } \\
\text { wittwet }\end{array}$ & $\begin{array}{l}\text { wet } \\
\text { pet. }\end{array}$ \\
\hline $\begin{array}{r}20-30 \\
30-35 \\
35-40 \\
40-45 \\
45-50 \\
50-55 \\
55-60 \\
60-70\end{array}$ & $\begin{array}{r}10 \\
20 \\
33 \\
27 \\
15 \\
17 \\
3 \\
3\end{array}$ & $\begin{array}{r}5 \\
11 \\
11 \\
5 \\
1 \\
-\end{array}$ & $\begin{array}{r}50 \\
55 \\
33 \\
18 \\
-6 \\
- \\
-\end{array}$ & $\begin{array}{r}5 \\
8 \\
8 \\
17 \\
17 \\
13 \\
10 \\
2 \\
1\end{array}$ & $\begin{array}{l}50 \\
40 \\
51 \\
63 \\
87 \\
60 \\
70 \\
-\end{array}$ & $\begin{array}{l}- \\
\overline{-} \\
\overline{1} \\
- \\
- \\
1\end{array}$ & $\begin{array}{l}- \\
- \\
- \\
- \\
-\end{array}$ & $\begin{array}{l}\ldots \\
-1 \\
1 \\
- \\
- \\
-\end{array}$ & $\begin{array}{l}- \\
- \\
3 \\
4 \\
- \\
- \\
-\end{array}$ & $\begin{array}{l}- \\
1 \\
4 \\
3 \\
2 \\
6 \\
1 \\
1)\end{array}$ & $\begin{array}{r}- \\
5 \\
10 \\
11 \\
13 \\
35 \\
30 \\
-\end{array}$ \\
\hline Summa . & 127 & 33 & 27 & 72 & 58 & 1. & 一 & 2 & - & 17 & 13 \\
\hline
\end{tabular}

Tabelle XI.

in Procenten:

\begin{tabular}{c|c|c|c|c|c|c}
\hline $\begin{array}{c}\text { Alter zur Zeit } \\
\text { des Todes. }\end{array}$ & $\begin{array}{c}\text { Zahl der } \\
\text { benutzten } \\
\text { Fälle. }\end{array}$ & ledig. & $\begin{array}{c}\text { ver- } \\
\text { ehelicht. }\end{array}$ & $\begin{array}{c}\text { ge- } \\
\text { schieden. }\end{array}$ & verlassen. & $\begin{array}{c}\text { ver- } \\
\text { wittwet. }\end{array}$ \\
\hline $20-30$ & 9 & 44 & 56 & - & - & - \\
$30-45$ & 80 & 33,7 & 52,5 & 1,2 & 2,5 & 10 \\
$45-60$ & 35 & 2,8 & 71,6 & - & - & 25,3
\end{tabular}

Die Durchsicht der verschiedenen Berufsarten der Unverheiratheten und die Berechnung der Aufnahmeziffer für die einzelnen Monate ergab durchaus nichts Charakteristisches und habe ich deshalb von der Anfstellung besonderer Tabellen abgesehen; nur ist hinsichtlich der Prostituirten Folgendes zu bemerken: Von den Unverheiratheten waren acht prostituirt, als sie in die Beobachtung eintraten, hierzu kam noch eine verheirathete Frau. - Hingegen war die Anzahl Derer, die überhaupt einmal erweislich unter sittenpolizeilicher Con-

Zeit des Todes gemacht. - Die Altersgruppe 60-70 ist bei der weiteren Berechnung nicht berücksichtigt und deshalb eingeklammert. 
trole gestanden hatten, viel grösser: 15 Unverbeirathete, 7 Verheirathete. Die Zahl 22 würde also derjenigen der Prostiuirten besser entsprechen; das siud 8,5 pCt. aller Paralysen (bei Siemerling $6 \mathrm{pCt}$.).

Endlich muss noch besonders daranf hingewiesen werden, dass auch meine Kranken mit wenigen. Ausnahmen den unteren und mittleren Volksschichten angehörten.

\section{Aetiologie.}

Es wurde bereits im Beginn dieser Arbeit darauf hingewiesen, dass die Anschaungen über die Aetiologie der progressiven Paralyse noch vielfach differiren, und dass dies besonders von der Würdigung der Syphilis gilt. Bei dem grossen Umfang der hierauf bezüglichen Literatur muss ich es mir versagen, hier den gegenwärtigen Stand der Syphilis-Paralyse-Frage eingehend zu referiren. Ich muss mich vielmehr darauf beschränken, in Kürze einen Ueberblick über die sich noch zum Theil entgenstehenden Ansichten zu geben.

Zunächst ist $\mathrm{zu}$ constatiren, dass die Zahl derjenigen, welche hente noch auf Grund ihrer Erfahrungen der Syphilis eine besondere Bedentung für die Entstehung der Paralyse absprechen, sich mehr und mehr verringert. Dieser Minderheit stehen in wachsender Mehrheit diejenigen gegenüber, welche in der syphilitischen Infection ein wichtiges ätiologisches Moment sehen. Allerdings ist die Stellung, welche derselben im Verbältniss zu den anderen Ursachen angewiesen wird, bei den einzelnen Autoren eine sehr verschiedene.

Während die Einen ihr blass eine gleichberechtigte Stellung neben den anderen Schädlichkeiten einräumen, betrachten die Anderen sie als die eigentliche und wahre Ursache der Krankheit. Dazwischen kommen alle möglichen Uebergänge vor. Den extremsten Standpunkt nimmt in dieser Hinsicht Möbius*) ein, welcher der Ansicht ist, dass Niemand an der progressiven Paralyse oder an der dieser sehr nahestehenden Tabes erkrankt, der nicht syphilitisch inficirt gewesen ist. Er giebt seiner Auffassung schon in der Zusammenfassung dieser beiden Krankheiten als "metasyphilitischer Nervenschwund" unzweideutigen Ausdruck. Daneben lässt er die anderen in Betracht kommenden Momente nur als Nebenbedingungen gelten. Unter diesen legt er dem „Uebermass an intellectueller und gemüthlicher Anstrengung mit Bezug auf die Paralyse einen besonderen Werth bei.

*) Möbius, Abriss der Lehre von den Nervenkrankheiten. Leipzig, 1893. S. 87. 
Die hierin zu Tage tretende Anschaung, dass die Paralyse, ebenso wie die Tabes, nur eine Nachkrankheit der Syphilis sei, wird im Wesentlichen auch von Strümpell*) getheilt, welcher sie als eine postsyphilitische, den anderen nach Infectionen eintretenden nervösen Störungen gleichzusetzende Intoxicationskrankheit ansieht.

Hiergegen geht $\mathrm{Erb}^{* *}$ ) mit Bezug auf die Tabes nicht so weit wie Möbius, wenn er auf Grund seiner umfassenden Stastistik die Ueberzengung ausspricht, dass es auch einzelne Fälle von Tabes obne vorhergegangene Syphilis giebt. Auch Hitzig***) spricht sich nur dahin aus, dass die übergrosse Mehrzahl der Tabischen früber ein venerisches Geschwür gehabt habe, er lässt also auch Ausnahmen gelten. - Wenn nun auch keineswegs Alles, was für die Aetiologie der Tabes festgestellt ist, ohne Weiteres für diejenige der Paralyse Geltung haben kann, bei welcher zweifellos gewisse andere speciell auf das Gehirn erschöpfend wirkende Momente eine nicht zu unterschätzende Rolle spielen, so können wir uns doch die Ausführungen der letatgenannten beiden Autoren nach verschiedenen Richtungen auch für die uns hier beschäftigende Krankheit zu Nutze machen. Ich denke hierbei insbesondere an Erb's Bemerkung über die auch scheinbar leichten Infectionen oft innewohnende Bedeutung (Vortäuschung einfacher Gonorrhoen durch Schankerinfectionen) und über das besonders bei Frauen häufige Latentbleiben sicher vorhandener Syphilis, ferner an die in neuester Zeit von Hitzig aufgestellte Hypothese, nach welcher die degenerativen Veränderungen des Centralnervensystems, wie wir sie bei der Tabes kennen, nicht als die Folgeerscheinung des eigentlichen syphilitischen, der primären Sklerose eigenthümlichen Virus, sondern als die eines anderweitigen Giftes anzusehen wären, welches ebensowohl bei dem syphilitischen Primäraffect als bei dem einfachen Schankergeschwür zur Entwickelung kommen kann. Es ist klar, dass diese Hypothese, auf die Paralyse übertragen, eine neue sehr interessante Perspective auf den ursächlichen Zusammenhang $z$ wischen dieser und den häufig festzustellenden

*) Strümpell, Lebrbuch der spec. Pathologie and Therapie. Leipzig, 1892. S. 216 und 448. No. 52 .

**) Erb, Dio Aetiologie der Tabos. Volkmann'sche Vorträge 1892.

- ***) Hitzig, Intorno alla Tabe traumatica ed alla Patogenesi della Tabo in generale. Comunicazioni all' XI. Congresso internat. med. ferner: Ueber traumatische Tabes und die Pathogenese der Tabes im Allgemeinen. Jubiläumfestschrift der Universität Halle 1894. (Sep.-Abdruck.) 
leichten, nicht eigentlich als syphilitisch geltenden Infectionen eröffnen würde*).

Die Ursachen, welche ausser der Syphilis für die Entstehung der Paralyse im Allgemeinen verantwortlich gemacht za werden pflegen, sind in einfacher Nebeneinanderstellung und obne damit etwas für den speciellen Werth jeder einzelnen von ihnen präjudiciren $z a$ wollen, folgende:

1. directe Heredität (Geistes- oder Nervenkrankheiten etc. bei den Eltern);

2. allgemeine neuropathische Belastung (Geistes- oder Nervenkrankheiten, psychische Anomalien etc. bei anderen Blutsverwandten);

3. allgemeine, die Widerstandsfähigkeit schwächende Momente (körperliche und geistige Anstrengung durch schwere Arbeit, Strapazen, Excesse in venere; unzweckmässige Ernährung, Alkoholismus; unregelmässiges Leben, wenig Schlaf);

4. psychische Ursachen (Sorgen, Kummer etc.);

5. gewisse körperliche oder geistige Ausnahmezustände:

a) physiologischer Art Gravidität - Klimacterium;

b) pathologischer Art vorausgegangene körperliche oder geistige Krankheiten; Entwickelungsanomalien etc.;

6. Traumen.

Für das männliche Geschlecht hat nun 0 ebeke die speciellen Beziebungen dieser verschiedenartigen Momente zu einander und zur

*) Hitzig spricht sich l.c. folgendermassen aus: „Sowohl die unitarisehe als die dualistische Lehre sind in ihrer Absolutheit unsicher. Bei der venerisehen Infection werden vielmehr mehrere Gifte entweder von vornherein geimpft oder doch schon in den ersten Stadien der Infection praducirt. Ein Gift, welches zunächst bei der primären Sklerose vorhanden ist, oder seine Abkömmlinge, führt zu secundären und tertiären Spätformen der Syphilis. Ein anderes Gift, welches in dem gleichen syphilitischen Geschwür vorhanden sein kann, aber nicht vorhanden zu sein braucht, oder seine Abkömmlinge, wird die Ursache einer eigenartigen krankhaften Veränderung der Blutmischung, die nach Jahre und Jahrzehnte langem Fortbestande des Lebens zu degenerativen Veränderungen des gesammten Nervensystems - allerdings in einer gewissen Stufenfolge der einzelnen Störungen - disponirt. Das gleiche Gift kann nicht nor in dem syphilitischen Primäraffect, sondern ebensowohl in dem Schankergeschwür, und zwar in beiden in grösserer oder geringerer Virulenz enthalten sein". 
Syphilis durch eine genaue Analysirung der Krankengeschichten von 100 Paralytischen klar zu stellen gesucht. Indem er diejenigen Fälle, in welchen Syphilis vorangegangen war und diejenigen, in welchen sich diese nicht nachweisen liess, getrennt betrachtet, sucht er zu ermitteln, wie oft bei dieser und bei jener Gruppe dieses oder jenes ätiologische Moment entweder allein oder mit anderen combinirt anzutreffen war. - Dabei erwies sich wiederum die Syphilis als der häufigste Factor, obgleich sie in einer erheblichen Anzahl von Fällen fehlte. Es folgten der Häufigkeit nach: die neuropathische Belastung - persönliche nervöse Anomalien - Alkoholmissbrauch, geistige Ueberarbeitung und Gemütsbewegungen, sexuelle Excesse, directe Erblichkeit, Strapazen, Trauma. - Bei der Paralyse ohne Syphilis fand er als die häufigste Einzelerscheinung in der Anamnese die geistige Ueberarbeitung und Gemüthsbewegungen, bei der Paralyse mit constanter Syphilis nach dieser selbst die neuropathische Belastung und sexuelle Excesse, namentlich aber die rein somatischen Schädlichkeiten zusammen genommen. Dieser Nachweis, dass in der Mehrzahl der Fälle mehrere ätiologische Momente nebeneinander wirksam sind, war seither an der Hand einer grossen Statistik noch nicht erbracht worden und bildet ein wesentliches Resultat der 0 ebeke'schen Arbeit.

Obwohl von vornherein anzunehmen ist, dass dieser Satz auch für die paralytischen Franen gilt, so ist es doch nicht angängig, die Schlüsse, welche sich aus der Oebeke'schen Arbeit ergeben, ohne Weiteres auf diese zu übertragen. Schon die einfache Erwägung, dass wir es hier ganz überwiegend mit Kranken der niederen Volksschichten zu thun haben, während bei den Männern die sogenannten gebildeten Kreise stark betheiligt sind, lehrt, dass bei den Franen ein Homent keine grosse Rolle spielen kann, welches bei den Männern wichtig ist: die geistige Ueberanstrengung. Ein um so grösseres Feld werden wir dafür bei diesen meist ärmlich und sorgenvoll lebenden Personen den anderen Momenten einräumen müssen, welche den Organismus schwächen, also insbesondere andauernder körperlicher Anstrengung, sei es durch Arbeit oder Excesse, bei gleichzeitiger schlechter Ernährung, ferner den Gemüthsbewegungen. In der That herrscht darüber bei den Autoren, die speciell über die Paralyse der Franen geschrieben haben, im Ganzen Uebereinstimmung, dass diese Schädlichkeiten ganz besonders häufig bei der Entstehung der Krankheit mitwirken; dies wird von Krafft-Ebing, Siemerling, Greppin, Westphal, Lojacono anerkannt. Dagegen werden andere Momente wiederum in ihrer Wirksamkeit sehr verschieden geschätzt. Was zu- 
nächst die ätiologische Bedeutung des Klimacteriums betrifft, welche, wie schon oben erwähnt, von Krafft-Ebing, Jung, in geringerem Masse von Mendel, Greppin n. A. betont wurde, so erscheint dieselbe in ihrer allgemeinen Gültigkeit sehr abgeschwächt durch die Untersuchungen von Siemerling, welcher gerade das präklimacterische Alter zum Ausbruch der Paralyse am meisten disponirt fand, und in keinem Falle einen sicheren Zusammenhang mit dem Klimacterium nachweisen konnte. - Nicht ganz so ablehnend spricht sich A. Westphal auf Grund seiner Statistik aus, doch fand er einen Zusammenhang mit dem Klimacterium nur in vereinzelten Fällen ( 5,4 pCt.). Auch Eickolt, Berg, Idanow, Lojacono legen auf dieses Moment keinen besonderen Werth.

Mit noch geringerer Berechtigung wären gewisse andere physiologische Vorgänge im Leben des Weibes für die Entstehung der ParaIyse principiell verantwortlich zu machen, so die Gravidität, das Puerperium und die Lactation, wie das schon von Mendel betont wird. Die in geringer Anzahl von Jung;, Schmidt*), Hoche**), Eickolt a. A. beschriebenen, hierher gehörigen Fälle, zu denen noch je eine Beobachtung von Siemerling and A. Westphal kommt, bestätigen meist, so weit sie einwandsfrei sind, nur die Annahme, dass körperlich schwächende Momente aller Art gelegentlich den Anstoss zum Auspruch der Erkrankung geben können; die Fälle, in denen jegliche andere Ursache fehlt (wie z. B. in dem von Siemerling beschriebenen Falle), sind so vereinzelt, dass man daraus keine weiteren Schlüsse ziehen kann.

Dies gilt auch von den traumatischen Einflüssen, welche nicht selten bei bis dahin ganz gesunden Individuen ein der progressiven Paralyse conformes Krankheitsbild hervorrufen können. Ob dies wirklich echte Paralysen sind, erscheint mir für eine Anzahl der beschriebenen Fälle noch zweifelhaft. - Weit häufiger wirken die Traumen, wie übrigens auch die puerperalen Vorgänge, nur mittelbar mit anderen Ursachen zusammen oder sie führen eine Verschlimmerung schon vorhandener krankhafter Störungen herbei. - Auch über die Bedeutung der hereditären Belastung gehen die Meinungen noch auseinander. Hierbei ist aber zu bedenken, wie schwierig es ist, gerade über diesen Punkt zuverlässige anamnestische Daten zu erhalten. Deshalb

*) M. Schmidt, Beiträge zur Kenntniss der Puerperalpsychosen. Dieses Arohiv Bd. XI. S. $87 \mathrm{ff}$.

**:) L. Hoche, Ueber puerperale Psychose. Dieses Arohiv Bd. XXIV. S. 612 . 
wird man gut daran thun, aus den betreffenden Zahlen noch keine definitiven Schlüsse zu ziehen.

Diese Schwierigkeit macht sich nun in noch höherem Masse geltend bei der Beurtheilung des Verhältnisses zwischen Syphilis und Paralyse der Frauen. Wenn der Nachweis der stattgebabten Infection schon bei den Männern oft schwer zu führen ist, so wird derselbe bei den Frauen in vielen Fällen vollends zur Dnmöglichkeit; sei es, weil diese ebenso wenig wie die Angehörigen etwas von der Ansteckung gemerkt haben und nun alles bona fide ableugnen ( $\mathrm{Ju}$ mon's „Syphilis ignorée“), sei es, weil sie dieselbe vergessen haben etc. - Da auch etwaige von einem Primäraffect herrührende Narben, welche beim Manne event. auf die richtige Spur leiten, in Folge ihrer Localisation beim Weibe trotz sorgfältiger Untersuchung oft nicht auffindbar sind, so ist es klar, dass wir hier sehr häufig unser Urtheil gänzlich auf gewisse indirecte Symptome gründen müssen.

Hieraus ergiebt sich bei den Frauen eine noch grössere Unsicherheit und eine noch geringere Verwerthbarkeit der Schlussfolgerungen wie bei den Männern; dies drückt sich auch in den von den verschiedenen Autoren für die Frauen gefundenen Zahlen aus, welche enorme Differenzen zeigen. - So fand Lojacono (Sicilien) bei 13 paralytischen Franen gar keine Syphilis, so dass er dieselbe für seine Beobachtungszeit (fünf Jahre) aus der Aetiologie der weiblichen Paralyse ganz eliminiren zu dürfen glaubt; Siemerling konnte eine sichere Infection in 11,1 pCt. seiner Fälle nachweisen, Reinhard in 14,2 pCt. und bei Mitrechnung seiner relativ zahlreichen Prostituirten in 29 pCt. Kaes (bei Einschluss der Prostituirten) in 24,5 pCt., $\mathrm{Ziehen}$ in $30-46$ pCt. - Jacobse ${ }^{*}$ ) fand sichere Syphilis in 32 , wahrscheinliche in 11 pCt.; A. Westphal sichere oder wahrscheinliche Syphilis in 40 pCt.; Minor in 50 pCt. und bei Hinznrechnung der zweifelhaften Fälle sogar in 87 pCt., endlich Idanow in mindestens 58 pCt. - Der letztgenanute Autor stellt dann noch eine Gesammtberechnung aus 221 den Arbeiten verschiedener Autoren entnommenen Fällen an und findet hier vorausgegangene Syphilis in 68 pCt., ohne indessen diese Zahl für eine definitive zu halten.

Zur Feststellung der ätiologischen Momente habe ich von meinen Fällen 173 verwerthen können, in denen genügende anamnestische Daten vorhanden waren.

Diese Fälle habe ich nach folgendem Princip in mehrere Grup-

*) Journal of mental science. Bd. 38. No. 161. April 1892. (Nach Ka $\theta$ s citirt.) 
pen vertheilt: der ersten Gruppe gehören diejenigen an (44. Fälle), in welchen mir die vorangegangene syphilitische Infection gesichert schien; in der zweiten Gruppe befinden sich die Fälle, in denen ich eine solche mit an Sicherheit grenzender Wahrscheinlichkeit annehmen zu dürfen glaubte (43 Fälle). Die dritte enthält die Fälle, in denen das Vorhandensein der Syphilis zweifelhaft war (48 Fälle), endlich die vierte diejenigen, in denen nichts für Syphilis sprach. (38 Fälle.)

Was das bei der Einweisung in die verschiedenen Gruppen beobachtete Verfahren betrifft, so habe ich zur ersten Gruppe natürlich in erster Linie gerechnet diejenigen Fälle, in denen objective Zeichen noch bestehender Lues vorbanden waren. Es waren dies zwei Frauen mit Leucoderma und Plaques, 1 mit einem frischen Uleus an der Unterlippe, 2 mit specifischen Augenerkrankungen (Iritis etc.), 2 mit typischen Drüsenschwellungen. Weiter habe ich bierzu gezählt diejenigen Fälle, in denen die Infection und charakteristische secundäre Erscheinungen sich anamnestisch feststellen liessen. Hieran schliessen sich die Beobachtnngen, in denen Syphilis des Mannes ausser durch die ihn betreffende Anamnese noch durch mehrere Aborte oder Frühgeburten der Frau oder frühes Sterben mehrerer Kinder sicher gestellt war. Demnächst sind hierher gerechnet diejenigen Fälle, in denen nur ganz vereinzelt normale Geburten, dafür aber Aborte in grösserer Anzahl stattgefunden hatten. Endlich handelt es sich noch um solche Kranke, welche bei entsprechender Lebensführung als Prostituirte, Kellnerinnen etc. eine antisyphilitische Spritz-oder Schmiercur zweifellos durchgemacht hatten.

In dieser Gruppe finden sich 33 verheirathete Frauen, unter diesen haben 11 niemals weder geboren, noch abortirt; bei den übrigen ist 3 mal nichts über Entbindungen, Aborte etc. zu eruiren gewesen. 19 mal haben zwar Entbindungen in wechselnder Zahl stattgefunden, die Kinder waren aber mit verschwindenden Ausnahmen nicht ausgetragen oder sie gingen früh zu Grunde. Erwähnenswerth ist besonders ein Fall mit 12 Aborten und 3 jung gestorbenen Kindern, ferner ein $z$ weiter mit 8 Aborten und ein dritter mit 6 Aborten obne lebende Kinder; - im ersteren Falle wurde übrigens die Infection ausdrücklich bestritten. -

Unter den Verheiratheten befanden sich zwei Franen, die vor der Ehe Kellnerinnen gewesen waren; eine hatte viele "Verhältnisse" gehabt und als Femme entretenue gelebt; eine war früher Puella publica gewesen. Von den 11 Unverbeirathéten waren zur Zeit des 
Eintritts in die Beobachtung Prostituirte 5, verschiedentlich wegen Sittenpolizeicontravention bestraft waren 3 .

Unter den Fällen dieser Gruppe befindet sich die älteste meiner Kranken, eine 66jährige Frau. Dieselbe hatte in der ersten Ehe 3 Kinder geboren, hatte dann im Alter von 61 Jahren zum zweiten Mal geheirathet und bereits nach 4 Monaten die Ehe wieder scheiden lassen. In dieser Zeit war sie vom Manne in unzweifelbafter Weise syphilitisch inficirt worden und 3 Jabre später an Paralyse erkrankt (Beobachtung von Siemerling).

Die Kranken der zweiten Grappe sind diejenigen, bei denen mehr indirecte Symptome von Syphilis vorhanden waren, und zwar wiederum vor Allem solche, in welchen neben normalen Geburten häufige Aborte etc., ohne andere Veranlassung aufgetreten waren, während von directen Infectionserscheinungen vielleicht nur ein weicher Schanker, eine Gonorrhoe etc. bei einem der beiden Gatten nachgewiesen werden konnte. Hierher sind ferner diejenigen Prostituirten gerechnet, welche sich während eines längere Zeit fortgesetzten excedirenden Lebens überbaupt wegen einer Geschlechtskrankheit in Behandlung befunden hatten, gleichgültig, welcher Art dieselbe gewesen war. Endlich befindet sich unter diesen Fällen die jüngste Kranke meiner Beobachtung, ein Mädchen von 21 Jahren, bei welchem hereditäre Syphilis sehr wahrscheinlich war.

Im Uebrigen fanden sich hier bei 37 Verheiratheten oder Verheirathetgewesenen 7 kinderlose Ehen; 12 Frauen hatten mehr oder weniger oft geboren, meist aber nicht ausgetragene oder sonst nicht lebensfähige Kinder. Sie waren zur Zeit der Aufnabme kinderlos. 13 andere Kranke hatten lebende Kinder, aber fast immer auch Aborte und Frühgeburten durchgemacht. In 5 Fällen war über diesen Punkt nichts Sicheres in Erfabrung zu bringen gewesen. - Eine hatte früher sicher, zwei andere wahrscheinlich unter sittenpolizeilicher Controlle gestanden. - Von den 6 Unverheiratheten war 1 bei der Aufnahme prostituirt, 2 andere waren es früher lange Zeit gewesen. 2 Mädchen hatten als Kellnerinnen gewirkt.

Die III. Gruppe enthält diejenigen Fälle, in denen unsichere Angaben gemacht wurden, so dass die Frage der Infection offen bleiben musste, obwohl oft Grund genug vorhanden war, eine solche zu vermuthen. - Erst hier habe ich diejenigen Personen mitgezählt, bei denen lediglich aus der Lebensführung an und für sich der Verdacht einer stattgehabten Infection hergeleitet werden konnte, also Prostituirte, Kellnerinnen, leicht zugängliche Modistinnen und Näherinnen etc., kurz alle die Personen, welche in der Grossstadt aus einer Hand in 
die andere gehen und deshalb einer specifischen Ansteckung jedenfalls besonders exponirt sind.

Hier fanden sich unter den 35 Verheiratheten 9 kinderlose Frauen, 6 hatten normale Geburten und Aborte gehabt, die Kinder aber bald verloren; 13 Frauen waren Mütter von einer mehr oder minder grossen Zahl normaler Kinder und hatten nur relativ selten Aborte durchgemacht. In 7 Fällen liessen die Angaben in dieser Hinsicht im Stich. - Unter den Verheiratheten befanden sich endlich 4, die sexuell stark excedirt hatten, ferner eine Frau, die wegen Sittenpolizei-Contravention früher bestraft war und Eine, die früher femme entretenue gewesen war.

Unter den 13 Unverheiratheten befand sich zwar nur eine, die zur Zeit der Aufnahme prostituirt war, 10 hatten aber früher sexuell excedirt und zum Theil unter Controle gestanden; nur bei zweien waren die Angaben ungenügend.

Die Fälle der letzten Gruppe, in denen die Infection auf das Bestimmteste bestritten wurde und auch keinerlei sichere Verdachtsmomente bestanden, setzen sich zusammen aus 30 Verheiratheten und 8 Unverheirathen. Unter den Ersteren befanden sich 14 kinderlose; in 13 Fällen waren gesunde Kinder (bei vereinzelten Aborten) vorhanden. In 3 Fällen endlich war die Anamnese nach dieser Richtung lückenhaft.

Unter den Unverheiratheten befand sich keine Prostituirte, dagegen Eine, die einmal sittenpolizeilich bestraft war. Von den übrigen 7 ist in dieser Hinsicht nichts zu sagen.

Erwähnenswerth ist noch, dass der II. Gruppe 2 Fälle zugerechnet sind, in denen der angeblich nicht inficirte Ehemann tabisch und einer, in dem er paralytisch war. Den letztgenannten Fall, welcher auch sonst von Interesse war, beabsichtige ich demnächst ausführlich zu publiciren.

Aus der vorstehenden Zusammenstellung ergiebt sich, dass in 88 von meinen 173 Fällen eine syphilitische Infection sicher oder fast sicher stattgefunden hatte, d. h. also in 50,8 pCt. Obwohl diese Ziffer schon verhältnissmässig hoch ist, glaube ich doch, dass sie dem thatsächlichen Verbältniss noch nicht einmal entspricht. Sie repräsentirt nur den Grenzwerth, bis zu dem die Syphilisinfection nachgewiesen werden konnte; mit grosser Wahrscheinlichkeit zu vermuthen ist eine solche aber auch in einer Anzahl von Fällen der Gruppe III. und sogar vereinzelt der Gruppe IV. Ich möchte hier beiläufig auf die Häufigkeit der kinderlosen Ehen hinweisen, welche auch vọ Kaes constatirt worden ișt (ein Drittel seinẹr Fälle). Unter 
117 Kranken meiner Beobachtung, in denen sorgfältig genug hierauf geachtet worden war, befanden sich 41 vollkommen sterile Franen, d. h. mehr als der dritte Theil oder in Procenten 36 pCt. Auf die einzelnen Gruppen vertheilen sich die Fälle so, dass die erste mit 36,6 , die zweite mit 22,0 , die dritte mit 31 und die vierte mit 47 pCt. betheiligt ist. Obwohl ich nicht in der Lage gewesen bin, eine Controlstatistik an nicht paralytischen Frauen anzustellen, so erscheinen mir doch die gefundenen Zahlen auffallend hoch.

In der Annahme, dass meine Syphilisstatistik mit 50,8 pCt. noch hinter der Wirklichkeit zurückbleibt, habe ich, ähnlich wie $\mathrm{Ziehen}$ dies gethan hat, der aus den zwei ersten Gruppen gewonnenen Ziffer, die ich als zu klein betrachte, die aus den drei ersten Gruppen sich ergebende gegenübergestellt, welche etwas zu gross sein dürfte. Es ergiebt sich dann für die Syphilis eine Procentziffer, die zwischen 51 und 78 liegt, und jedenfalls auch noch eher zu niedrig als zu hoch ist.

Ueber die Mitwirkung der übrigen Ursachen und ihre Vertheilung auf die einzelnen Gruppen giebt die nachfolgende Zusammenstellung einen allgemeinen Ueberblick. Hierbei muss aber berücksichtigt werden, dass auch diese Zahlen zum Theil als hinter der Wirklichkeit zurückbleibend angesehen werden müssen. Dies gilt insbesondere von den psychischen Ursachen und den körperlich schwächenden Momenten, welche bei der dürftigen äusseren Lage der Mehrzahl meiner Kranken ohne Zweifel viel häufiger vorhanden gewesen sind, als es nach den Angaben der Angehörigen' den Anschein hat.

\section{Gruppe I. (44 Fälle - Syphilis sicher.)}

Ausser der syphilitischen Infection konnten keine anderen Ursachen festgestellt werden: in 16 Fällen.

Syphilis fand sich combinirt mit einer der anderen Ursachen:

in 21 Fällen;

mit zwei anderen Ursachen:

in 5 Fällen;

mit drei anderen Ursachen:

in 2 Fällen.

Von diesen Ursachen waren vorhanden:

Directe Heredität . . . . . $3 \mathrm{mal}=7 \mathrm{pCt}$.,

Neuropathische Belastung. . . 4 , $=9$ "

Sexuelle Excesse . . . . $10 "=22,7$ "

Alkoholische Excesse . . . . $7_{n}=16$,

Psychische Ursachen . . . . $3 \%=7$ "

Frühere geistige Anomalien . . 2 n $=4,5$, 
Frühere körperliche Anomalien . $\quad 6 \mathrm{mal}=13,6 \mathrm{pCt}$.,

Trauma capitis. . . . . $2,=4,5$,

Gruppe II. (43 Fälle - Syphilis höchst wahrscheinlich.)

Ausser höchst wahrscheinlicher Syphilis konnte keine Ursache festgestellt werden: in 11 Fällen.

Höchstwahrscheinliche Syphilis war combinirt mit einer der anderen Ursachen:

$$
\begin{aligned}
& \text { in } 17 \text { Fällen; } \\
& \text { mit } z \text { wei derselben } \\
& \text { in } 9 \text { Fällen; } \\
& \text { mit drei derselben } \\
& \text { in } 5 \text { Fällen; } \\
& \text { mit vier derselben } \\
& \text { in } 2 \text { Fällen. }
\end{aligned}
$$

Im Speciellen waren vorhanden:

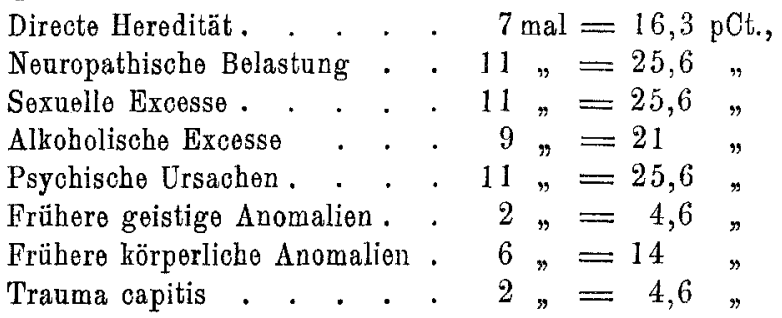

Gruppe III. (48 Fälle - Syphilis zweifelhaft.)

Ausser zweifelhafter Syphilis wurden keine Ursachen gefunden:

in 7 Fällen;

Bei zweifelhafter Syphilis war eine der anderen Ursachen vorhanden:

$$
\begin{aligned}
& \text { in } 19 \text { Fällen; } \\
& \text { zwei Ursachen } \\
& \text { in } 14 \text { Fällen; } \\
& \text { drei Ursachen } \\
& \text { in } 6 \text { Fällen; } \\
& \text { vier Ursachen } \\
& \text { in } 2 \text { Fällen. }
\end{aligned}
$$

Im Speciellen waren vorhanden:

$$
\begin{aligned}
& \text { Directe Heredität . . . . . } 12 \mathrm{mal}=25 \mathrm{pCt} \text {., } \\
& \text { Neuropathische Belastung . . } 10 \%=20 \text { ” } \\
& \text { Sexuelle Excesse . . . . . } 25 "=52 \text { " } \\
& \text { Alkoholisohe Excesse . . . } 7 \%=14,6 \text {, }
\end{aligned}
$$


Statistisches und Klinisches zur Kenntniss d. paralyt. Geistesstörung. 507

Psychische Ursachen . . . . $12 \mathrm{mal}=25 \mathrm{pCt}$.,

Frühere geistige Anomalien . . $1 n=2$ "

Frühere körperliche Anomalien . $\quad 3 n=6,2$ n

Trauma capitis . . . . $3 \%=6,2$ "

Gruppe IV. (38 Fälle - Syphilis nicht vorhanden.)

Gar keine Ursache war auffindbar

in 5 Fällen;

eine Ursache war vorbanden

in 13 Fällen;

zwei Ursachen

in 14 Fällen;

drei Ursachen

in 6 Fällen.

Im Speciellen ergiebt sich:

Directe Heredität . . . . $9 \mathrm{mal}=23,7 \mathrm{pCt}$.,

Neuropathische Belastung . . $5 n=13,1$,

Sexuelle Excesse . . . . . $5 "=13,1$ "

Alkoholische Excesse . . . $5 "=13,1$ "

Psychische Ursachen. . . . $16,=42,1$,

Frühere geistige Anomalien . . $5 "=13,1$ "

Frühere körperliche Anomalien . $7,=18$ "

Besondere körperl. Anstrengungen $5 n=13,1$ "

Trauma capitis . . . . $2 \%=5$ "

Aus dieser Zusammenstellung ergiebt sich folgendes:

Stellen wir einfach die Anzahl der benutzten Fälle der Anzahl sämmtlicher überhaupt nachgewiesener Ursachen gegenüber, so finden wir im Ganzen auf 173 Fälle 315 Ursachen notirt, d. h. für jeden Fall annähernd zwei Ursachen. Dass diese Zahl thatsächlich, wie oben angedeutet, hinter der Wirklichkeit zurückbleibt, wird besonders deutlich, wenn wir die Häufigkeit der einzelnen Ursachen nicht für jede Gruppe allein, sondern mit Bezug auf die Gesammtheit der Fälle ausrechnen. Es zeigt sich dann, dass z. B. die „psychischen Ursachen“ in 173 Fälle nur 42 mal figuriren ( 24 pCt.), und dass unter den erschöpfenden Momenten, abgesehen von den Excessen verschiedener Art, nur $5 \mathrm{mal}$ besondere körperliche Anstrengungen aufgeführt sind (ca. $3 \mathrm{pCt}$.). Das Gleiche gilt in geringerem Masse auch von der Häufigkeit der directen Heredität und der allgemeinen neuropathischen Belastung, welche mit 18 bezw. 17 pCt. ohne Zweifel ebenfalls zu niedrig veranschlagt sind, endlich wohl auch von den Excessen in Venere et Baccho, welche zusammengenommen mit 45,6 pCt. notirt sind. - Die 
anderen Ziffern dürften der Wirklichkeit besser entsprechen, so z. B. die Betheiligung der traumatischen Einflüsse mit 5 pCt. - Weiterhin ist zu berücksichtigen, dass bei der vorstehenden zusammenfassenden Berechnung sämmtliche Fälle der III. und IV. Gruppe als nicht syphilitisch betrachtet sind, was zwar für die Mehrzahl derselben aber keineswegs für alle zutriff. Auch hierdurch wird also die absolute Zahl der wirksamen Schädlichkeiten noch herabgedrückt.

$\mathrm{Nach}$ allem diesem scheint es mir ausser Frage zu stehen, dass auch in meinen Fällen immer mehrere und zwar zum mindesten zwei ätiologische Momente zusammengewirkt haben.

Es bedarf noch einiger Worte über die Beziehungen der einzelnen Ursachen zu einander mit Rücksicht auf die Häufigkeit, in der sie nachgewiesen werden konnten *).

Wenn wir die sämmtlichen 173 Fälle berücksichtigen, so finden wir am häufigsten die Excesse (in Venere et Baccho) mit 45,6 pCt. Es folgen die directe Heredität und die allgemeine neuropathische Belastung zusammengenommen mit 35 pCt., sodann die psychischen Ursachen mit 24 pCt. und endlich die übrigen, unter denen die Traumen die letzte Stelle einnehmen. - Ebenso gestaltet sich die Häufigkeitsskala innerhalb jeder einzelnen Gruppe mit Ausuahme der vierten. So finden wir in

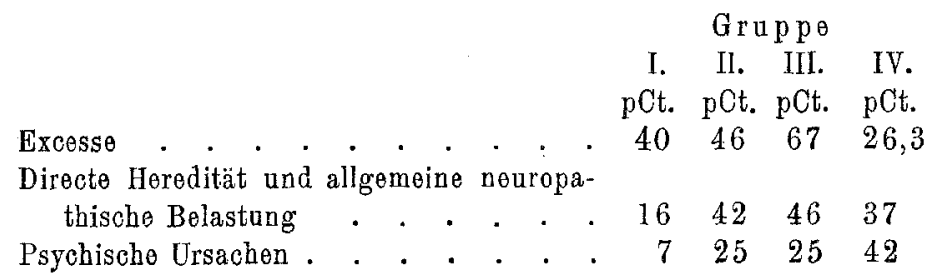

In der 4. Gruppe nehmen also die psychischen Ursachen die erste Stelle ein. Dieser Umstand erscheint mir deshalb nicht bedeutungslos, weil gleichzeitig diejenigen Schädlichkeiten, deren anamnestische Feststellung noch mit relativ grosser Sicherheit möglich ist, nämlich die Excesse, an die letzte Stelle rücken. Hiernach würden also in den Fällen, in denen eine syphilitische Infection fehlt, die psychisehen Ursachen die Hauptrolle spielen.

Bezüglich der übrigen ätiologischen Momente ist noch Folgendes zu bemerken:

Die Fälle, in denen dem Ausbruche einer Paralyse eine andere

*) Hierbei ist von der Lues immer abgesehen. 
Psychose vorangegangen ist, sind bekanntlich sehr selten. Ich denke hierbei nicht an das von einigen Beobachtern behauptete*) Hinzutreten einer „secundären“ Paralyse zu einer anderen Geistesstörung, wie ich es niemals gesehen, ebensowenig an gewisse mehr oder weniger verschwommene psychische Abnormitäten, wie sie sich im Prodromalstadium der Paralyse nicht selten finden, sondern an selbstständige, wohl umgrenzte und auch zeitlich scharf von der letzteren getrennte Krankheitsbilder. Bei der Durchsicht der von mir benutzten Literatur finde ich bei $\mathrm{Mendel}^{* *}$ ) nur zwei derartige Fälle erwähnt: der eine betrifft einen 44 jährigen Mann, der mit 20 Jahren eine hypochondrische Melancholie mit Suicidversuch durchgemacht und dann 23 Jahre lang nichts Krankhaftes dargeboten hatte, bis er an sicherer Paralyse erkrankte. In dem anderen Falle handelte es sich um einen Offizier, der als Lieutenant im Jahre 1856 wegen einer "Manie mit Hallucinationen“ längere Zeit in Anstaltsbehandlung stand und nach langer Dienstzeit 1870 als Oberst an Paralyse erkrankte.

Ferner beschreibt Eickbolt***) einen derartigen Fall. Derselbe betraf einen männlichen Patienten mit schwerer erblicher Belastung, welcher im Alter von 20 Jahren mit Tobsucht erkrankte und 11 Jahre nach seiner Genesung eine Paralyse acquirirte.

Berg $\dagger$ ) hat mehrere Fälle verzeichnen können, in denen bereits vor der Paralyse eine Geistesstörung aufgetreten war. Eine der Patientinnen, welche bei der Aufnahme wegen Paralyse etwa 46 Jahre alt war, hatte sich bereits mit 14 Jahren in einer Irrenanstalt befunden; in einem zweiten Falle war 29 Jahre vor Beginn der Paralyse ein Erregungszustand aufgetreten, welcher eine dauernde Reizbarkeit in dem Wesen der Kranken zurückgelassen hatte; eine dritte Kranke hatte ein Delirium potatorum und später noch eine andere Geistesstörung überstanden.

Weiter berichtet Hougberg什) von 6 Fällen, in denen eine primäre Geisteskrankheit der Paralyse vorausgegangen war.

Endlich ist hier noch zu verweisen anf die oben bereits erwähnte Arbeit von Philipp Rey†t†), welcher das bäufige Vorkommen der

*) Vergl. Höstermann, Ueber secundäre progressive Paralyse. Allg. Zeitschrift f. Psychiatrie Bd. 32. S. $333 \mathrm{ff}$.

**) Mendel, Monographio S. 241, 242.

***) Eickholt l. c. S. 41 .

†) Berg l. c. S. 50 .

t+) 1. c. S. 74 .

t†) l. c. 
Paralyse bei Hysterischen betont und mit Beispielen belegt, und auf die Notiz bei Kaes*), welcher abgesehen von einigen Fällen, in denen Imbecillität bestand, Hysterie $1 \mathrm{mal}$, Epilepsie 7 (4 Männer, 3 Frauen) und Chorea $1 \mathrm{mal}$ in der Vorgeschichte seiner Kranken nachweisen konnte.

In Bezug auf diesen Punkt ergiebt nun meine Statistik ein fast negatives Resultat. In keinem meiner Fälle konnte das frühere Bestehen einer Psychose nachgewiesen werden, wenn man von einigen originär schwachsinnigen, von jeher excentrischen oder mit allerhand Sonderbarkeiten behafteten Personen absieht. - In vereinzelten Fällen waren früber Erscheinungen von grande Hystérie vorhanden gewesen. Chorea war einmal mit der Paralyse gleichzeitig vorhanden. Nur in einem Falle war alte Epilepsie nachweisbar. - Bei einer Prostituirten bestand von jeher conträre Sexualempfindung.

Die Rubrik „voraufgegangene körperliche Anomalien“ enthält alle Fälle, in denen eine Schwächung des Organismus durch irgend welche voraufgegangenen körperlichen Schädlichkeiten incl. Gravidität angenommen werden konnte. Die gegebenen Zahlen haben nur bedingten Werth, weil auf diesen Punkt nicht immer genau geachtet ist. - Einige Fälle meiner Beobachtung, in denen ein Zusammenhang der Paralyse mit einer vorausgegangenen Kopfverletzung zu bestehen schien, seien hier kurz angeführt.

\section{Beobachtung 1 .}

Henriette R., Rentiersfrau, 60Jahre alt, in guten äusseren Verhältnissen, erblich nicht belastet, angeblich keine Lues. Verheirathet seit $31 \mathrm{Jahren}$, hat 7 Entbindungen und einen Abort durchgemacht. -3 Kinder leben, 4 sind an indifferenten Kinderkrankheiten klein gestorben. Patientin, die früher ganz gesund gewesen ist, erhielt vor 3 Jahren bei einer Schlägerei, in die sie zufällig verwickelt wurde, mehrere heftige Schläge gegen den Kopf und erlitt erbebliche äussero Verletzungen. Seit dieser Zeit besteht Zerstrentheit, Gedächtnissschwäche, unmotivirter Stimmungswechsel. - Später trat Kopfschmerz hinza und Unfähigkeit, die Wirthschaft zu besorgen; keive Krämpfe, keine Ohnmachtsanfälle. Seit einigen Wochen vor der Aufnahme besteht gehobene Stimmung, grosse Reizbarkeit, Besobäftigungsdrang, Verschwendungssucht, typisohes Grössendelirium and Zerstörungswath.

Bei der Aufnahme (11. November 1887) sehr vergnügt, hat 200000 Thaler Vermögen, hofft aber bald eine Million zu besitzen, da sie noch jung sei. Prahlt mit den 11 Häusern, die sie schon habe, und will noch $1000^{\circ}$ andere banen, besitzt unschätzbare Diamanten, will Morgen den Papst besuchen etc.

Körperliche Untersuchung: Seniler Habitus. - Pupillen different.

*) I. c. S. 647 . 
Lichtreaction etwas träge. - Deutliche paralytische Sprachstörung. - Kniephänomen links otwas gesteigert. Am 1. December 1887 ungeheilt entlassen (ans der Beobachtung).

\section{Beobachtung 2.}

Frau R., Schankwirthsfrau, 45 Jahre alt. - Mutter starb an Gehirnschlag, sonst keine erbliche Belastung. - Seit 1869 rerbeirathet. Ein uneheliches Kind starb früh. - In der Ehe mehrmals Aborte ron 1-2 Monaten. Periodo sebr unregelmässig (Klimacterium). - Geistig soll sio früher gesund gewesen sein.

Im Jahre 1884 verunglückte sie bei einem Eisenbahnunfall (Steglitz); trug versehiedene Verletzungen auch im Gesieht und am Kopf davon, wurde bewusstlos unter Leichen vorgezogen. Seit dieser Zeit soll sie gedaukenschwach und aufgeregt sein und auch an Kopfschmerzen leiden. Später klagte sie viel über Schlaflosigkeit. - Seit oinem Jahre bat die Aufgeregtheit zugenommen, sie wurde auch vergesslich, zerstreut, ging unvorsichtig mit Geld um, hatte selbst das Gefühl der erschwerten Sprache; in letzter Zeit machte sie unnütze Einkäufe. - Am 23. Februar 1889 Aufnahme in die Charité. Hier ergab die Untersuchung: körperlich Pupillendifferenz. - Lichtreaction links träge, rechts erloschen. - Typische Sprachstörung. - Kniephänomen gesteigert. - Geistig: Schwachsinn - Vergesslichkeit. - Grössenideon (viele Talente, körperliche Sebönbeit, kostbare Kleider). - Am 28. November 1889 Ueberführung nach Dalldorf. - Entwickelung neuer Grössenideen. - Psychische Schwäche. - Juli 1890 nach einer Filiale verlegt. Gestorben. - Sectionsresultat nicht bekannt.

\section{Beobachtung 3 .}

Laura Sch., verwittwet, 39 Jahre alt, Mäntelnäherin. Mutter war lüderlich, mit dem Vater blutsverwandt, sonst von Heredität nichts bekannt, will früher bis anf körperliche Krankheiten gesund gewesen sein, aber ein Jahr vor der Aufnahme monatelang an Dysmenorrhoe gelitten haben. - Hat Lues angeblioh nicht gehabt. - Eine Entbindung. - Kind klein gestorben. 1884 fiel sie in Folge eines Febltrittes eine steinerne Treppe hinunter, zog sich eine Vorderarmfractur und eine erhebliche Contusion der rechten Schläfegegend zu, verlor dabei das Bewusstsein, - Nach der Verletzung Gefühl des Hohlseins in der rechten Schläte, des Stechens im Kopfe, der Schwere in den Beinen. - Später Grössenideen und gemeingefäbrliche Handlungen. Aufnahme in die Charité am 20. April 1889. - Status praesens: Körperlich Narben im Gesicht. - Pupilion gleioh, Liohtroaction erhalten. - Typischo Sprachstörung. - Beben der Gesichtsmuskeln. - Kniephänomen sehr gesteigert. - Geistig: hochgradige Demenz. - Euphorie. - Am 2. Mai 1889 Ueberführung nach Dalldorf. Weitere Verblödung. - Reizbarkeit. - Unsauberkeit. - Nach einer Filiale verlegt. 


\section{Beobachtung 4 .}

Bertha H., Fuhrwerksbesitzersfrau 33 Jahre alt; Grossvater an Schlag. anfall gestorben; Cousine gelähmt, sonst keine Heredität. - Geordnete Verhältnisse. - Koine Kinder, keine Aborte. - Ehemann hat for der Verhoirathung einen Schanker gehabt, der bei localer Behandlung ohne Secundärerscheinungen geheilt ist. - Patientin ist ganz normal gewesen bis vor zwei Jahren. - Damals bei der Arbeit Fall von einer Treppe mit Verletzung des Gesichts. Kein Bewusstseinsverlust. - Einige Zeit darauf traten Kopfsehmerzen, Ohnmachtsanfälle, Erbrechen, voräbergehende Sprach-und Extremitätenlähmung ein. - Die Wirthschaft konnte sie wegen Gedächtnissschwäche seit 2 Jahren nicht mehr besorgen. - Andauernde Erschwerung der Sprache. Vorübergehende linksseitige Amaurose nach einem der häufigen epileptiformen Anfälle. - Aufnahme in die Charité am 9. Juni 1889. - Status. Körperlich: Sattelnase. - Keine sicheren Anzeichen von Lues. - Decubitas. - Differenz der Facialisinnervation. - Sprachstörung. - Parese des linken Armes und Beines. - Narben an der Stirn und am Nacken. Leistendrüsen geschwollen. Pupillen different; Lichtreaction fehlt links. Kniephänomen fehlt rechts. Goistig: Demenz. Euphorie.

Am 4. Juli 1889 Ueberführung nach Dalldorf. Dort im Wesentlichen Statas idem. - Tod am 24. Juli 1889. - Section: Pachymeningitis chron. ext. et int. levissima. Periencepbalitis chron. diffusa. Dilatatio ventrioulorum. Todesursache: Preumonie.

\section{Beobachtung 5 .}

Anna K., Schankwirthsfrau, 37 Jahre alt. - Angeblich keine Heredität. - Verheirathet seit 1874. - 4 Kinder lebendgeboren, von denen 2 an Kinderkrankheiten, eines an Lebensschwäche gestorben sind; eines lebt und ist gesund. - Ferner ein Abort. - Lues gelengnet, mässiger Potus eingeräumt. Vor 2 Jahren Kopfverletzung. Kein Bewusstseinsverlust. Schon 2 Jahre vorher Kopfreissen. - Vor $1 \frac{1 / 2}{2}$ Jahren erste Zeichen ron Geistesstörung, machte ganz Verkehrtes, lachte ohne Grund, war 3 Tage lang verwirrt, konnte nicht ordentlich sprechen. Seit diese Zeit fortschreitender reizbarer Schwachsinn. Oefter Anfälle vorübergohonder Benommenheit mit Vorsichhinstarren; keine Zuckungen. - Aufnahme in die Charité am 28. März 1891.

Status. Körperlich: Pupillen-Lichtreaction fehlt. Typische Sprachstörung. - Kniephänomen gesteigert. Ge istig: Demenz, Euphorie. - Stimmungswechsel. - Am 9. April 1891 nach Dalldorf überführt. Hier Status idem. - Einige Male leichte paralytische Anfälle. Zuckungen einzelner Gesichtsmuskeln, Schütteln des Kopfes, automatische Bewegungen. 17. Ootober 1891 Exitus.

Section: Leptomeningitis chronica. Hydrocephalus internus. Ependymitis granulosa. - Todesursacho: Marasmus. 


\section{Beobachtung 6 .}

Pauline B., Sehuhmacherfrau, 33 Jahre alt. - Heredität, Lues, Potas bestritten. - Geordnete Verhältnisse. - 2 Kinder leben und sind gesund. Patientin war selbst immer gesund. Vor 6 Jahren Kopfyerlotzung (Aufschlagen mit der Stirn auf die Wasserleitung), keine Bewusstlosigkeit, keine sichtbaren Folgen. - Vor 2 Jahren erster Schlaganfall mit rasch vorübergehender Lähmung. Danach Abnahme des Gedächtnisses. Weiterhin mehrfach leichtere Anfälle ohne Bewusstseinsverlust, ohne Krämpfe. Vor 5 Wochen Verwirrtheit mit Hallucinationen.

Aufnabme in die Charité am 7. September 1888.

Status. Körperlich: Narbe an der Stirn. - Pupillen different. Liohtreaction vorhanden. - Gravidität. - Kniephänomen gesteigert. - Typische Sprachstörung. - Beben der Gesichtsmuskeln. Goistig apathische Demenz.

Ueberführung nach Dalldorf am 13. September 1888.

Hier im Wesentlichen Status idem. - Euphorie. - Entbindung von einem todten Kinde am 18. September 1888. Exitus letalis am 17. Januar 1889.

Section: Exostoses cranii interni. Leptomeningitis chronica. Adbaesiones piae ot corticis. Hyjdrocephalus internus.

\section{Beobachtung 7.}

Ghristine L., Arbeiterfrau, 31 Jahre alt. - Heredität bestritten; Lues desgleichen. - Verheirathet seit 1883. Niemals Entbindungen oder Aborte. Immer träge, dabei heftiges "nervöses" Wesen. - Vor 3 Jahren Gemüthsbewegungen. - Vor 2 Jahren Kopfverletzang mit Verlust des Bewusstseins für $1 / 4$ Stunde. Seitdem Kopfschmerzen, Schwindel, noch träger als vorher. Hallucinationen im Sinne der Beeinträchtigurg.

Aufnahme in Charité am 9. Mai 1891.

Status. Körperlich: Papillen diffèrent; Liehtreaction träge. Typische Sprachstörung. - Westphal'sches Zeichen. - Geistig: Hochgradigste Demenz. - Ueberführung nach Dalldorf am 28. Mai 1891. Hier im Wesentlichen Status idem; am 7. Juni 1891 Exitus lotalis.

Section: Pachy- et Leptomeningitis chron. diffusa. Dilatatio ventric. lateralis. Oedema cerebri.

\section{Beobachtung 8.}

Bertha H., Maurerswittwe, 46 Jahre alt. - Heredität angeblich nicht vorhanden. - Patientin war zweimal verheirathet, hatte aus erster Ehe ein Kind; zweite Ehe kinderlos. - Abgesehen ron Sirnkopfschmerzen rollkommene Gesundheit bis zum Anfang dieses Leidens. - Im Jahre 1889 fiel sie auf der Strasse mit der Stirn auf's Steinpflaster, wurde besinnungslos nach Hause gebracht, kam erst nach einer Stunde za sich. Seitdem klagte sie über 
Schwindel, hatte Ohnmachtsanfä̈le, redete verwirrt, besorgte die Wirthschaft schlecht, machte Verkehrtheiten. - Mehrfach auch epileptiforme Zustände von circa halbstündiger Dauer. - Allmälig Verschlechterung des psychischen Verbaltens, wurde ganz kindisch, sass den ganz Tag unthätig, erzäblte von grossen Reichthümern. - Die Sprache wurde immer schlechler und schliesslich fast unverständlich. - Seit 4-5 Jahren Struma.

Aufnahme in die Charité am 16. Juni 1891, nach Dalldorf 25. Juni 1891. Status. Körperlich:Schlechter Ernährungszustand. - Narbo an der Stirn. - Pupillen different, weit, Lichtreaction links träge, rechts feblend. Hochgradige Sprachstörnng. - Deutliche Struma. - Herztöne rein. - Puls 120. - Starkes Pulsiren der Halsarterien. - Dankelbraune Pigmentirung grösserer Körperabschnitte. - Schleimhä口te frei. Kein Exophthalmus, kein Grae fe'sches Symptom, Leichter Tremor der gespreizten Finger. - Sehnenreflexe der oberen Extremitäten gesteigert; Kniephänomen lebhaft. - Mechanische Muskelerregbarkeit gesteigert. - Geistig: Kindisches Wesen, hochgradige Demenz (Dr. Köni g).

17. November 1891 in Pflege entlassen.

7. November 1892 wieder aufgenommen. - Struma geringer. Sonst Status idem. - Geistig: Demenz, Unrube; Nabrangsverweigerung. Sopor. Subnormale Temperaturen.

3. Januar 1893 Exitus letalis.

Section: Pachymeningitis externa adhaesiva et interna baemorrbagica recens. Leptomeningitis chronica. Hydrocephalus levissimus. Hyperaemia cerebri et medallae spinalis.

Todesursache: Marasmus.

Dass es sich in den vorgenannten Fällen um Paralyse gehandelt hat, scheint mir bei der Eigenart des klinischen Bildes auch da unzweifelhaft, wo die Diagnose nicht durch die Autopsie bestätigt werden konnte. - Wir sehen nun, dass nur in der ersten Beobachtung die Kopfverletzung als das einzige ätiologische Moment angegeben wird. Diese Kranke befand sich in günstigen äusseren Verhältnissen und hatte mit den Sorgen des täglichen Lebens nicht zu kämpfen; auch von den anderen Schädlichkeiten, insbesondere der Lues, findet sich nichts in der Anamnese. Wenn man nicht in den durch das Senium bedingten Rückbildungsvorgängen ein prädisponirendes Moment erblicken will, muss man also diesen Fall als einen von denjenigen betrachten, in denen lediglich das Trauma die charakteristischen Krankheitserscheinungen hervorgerufen hat.

Dagegen lassen sich in sämmtlichen anderen Beobachtungen noch andere Schädlichkeiten nachweisen; so ist in Beobachtung 3 hereditäre Belastung, daneben wahrscheinlich auch eine oder die andere 
psychische Ursache vorhanden gewesen. In Beobachtung 6 hat sich die Paralyse während einer Schwangerschaft, die mit der Geburt eines todten Kindes endete, entwickelt, ausserdem liegt hier zwischen dem Trauma und der Erkrankung ein Zeitraum von 4 Jahren, welcher den Zusammenhang immerhin zweifelhaft erscheinen lässt; in Beobachtung 5 mahnt der Alkoholismus und das Vorhandensein von „Kopfkolik" bereits 2 Jahre vor dem Trauma gleichfalls zur Vorsicht in der Deutung.

Die Kranke der Beobachtung 7 war immer nervös und heftig gewesen, hatte in ungünstigen häuslichen Verbältnissen gelebt und war in 8 jähriger Ehe steril geblieben. - Das Letztere war auch bei der Kranken No. 4 der Fall, deren Mann eine Schankerinfection durchgemacht hatte und bei der ausserdem hereditäre Belastung feststeht. In Fall 2 ist mit Rücksicht auf die überstandenen Aborte der Verdacht einer vorausgegangenen Luesinfection nicht von der Hand zu weisen, ausserdem mag hier das Klimacterinm mitgewirkt haben. Endlich war in Fall 8 in dem jedenfalls schon längere Zeit bestehenden Morbus Basedowii, der wahrscheinlich mit Morbus Addisonii combinirt war, ein prädisponirendes Moment gegeben, ausserdem haben in diesem Falle möglicherweise paralytische Erscheinungen leichter Art bereits zur Zeit des Traumas bestanden.

Immerhin sind auch diese Fälle ein weiterer Beleg dafür, dass durch traumatische Einflüsse sowohl bereits bestehende leichte Krankheitserscheinungen versehlimmert als auch gelegentlich, wenn auch ziemlich selten, bei sonst disponirten Individuen Krankheitsbilder hervorgerufen werden können, welche nicht nur klinisch, sondern auch makroskopisch-anatomisch der progressiven Paralyse durchaus conform sind, während eine ganz reine traumatische Paralyse jedenfalls zu den Seltenheiten gehört.

\section{Klinisches.}

Dnter den körperlichen Symptomen nimmt das Verhalten der Papillen ein hervorragendes Interesse in Anspruch. Ich fand eine Differenz derselben in $55 \mathrm{pCt}$. meiner sämmtlichen Fälle. Die von verschiedenen Autoren erörterte Frage, ob die rechte oder die linke Pupille häufiger die weitere war, halte ich für vollkommen gleichgültig und habe sie nicht berücksichtigt.

Zur Beurtheilung der Lichtreaction habe ich nur einen Theil meiner Fälle, 178, verwerthet, in denen eine specialärztliche Untersuchung stattgefunden hatte. Die Methode dieser Untersuchung war die von 
Uhthoff angewendete, welche zur Vermeidang unangenehmer Beobachtungsfehler warm zu empfehlen und, obwohl sie noch einigen guten Willen bei dem zu Untersuchenden voraussetzt, auch bei Geisteskranken in der grossen Mehrzahl der Fälle ausfübrbar ist. Bei der grossen Bedeutung, welche eine einheitliche Untersuchungsmethode für die Vergleichbarkeit der von verschiedenen Untersuchern erhobenen Befunde hat, sei es gestattet, die von Uhthoff seiner Zeit gegebene Schilderang wörtlich zu citiren*).

Für meine Fälle ergab sich Folgendes:

Erloschene Lichtreaction bei 50 pCt.

(Doppelt- oder einseitig.) Darunter 31,4 pCt. Pupillendiffereuz.

Veränderte (träge oder geringe) Lichtreaction bei 30 pCt.

(Doppelt- oder einseitig.) Darunter 16,2 pCt. Pupillendifferenz.

Erhaltene Lichtreaction bei $20 \mathrm{pCt}$.

Es ist sebr bemerkenswerth, dass sowohl Siemerling als auch A. Westphal reflectorische Pupillenstarre in 50 pCt. ihrer Fälle, also genau so oft wie ich gefunden haben. - Hingegen zeigen die anderen Zahlen insofern Differenzen, als Ungleichheiten der Pupillen von Siemerling nur in 26 pCt., von Westphal in 45 pCt. (von mir in 55 pCt.), veränderte Reaction von jenem in 14 , von diesem in 26 pCt. (von mir in $30 \mathrm{pCt}$.), endlich erhaltene Reaction in 36 und $24 \mathrm{pCt}$. (von mir in $20 \mathrm{pCt}$.) gefunden worden ist.

Im Uebrigen ergaben die Augenuntersuchungen Folgendes: Opticusatrophie $7 \mathrm{mal}$ ausgesprochen,

Abblassung der Papille (zum Theil sicher beginnende Atrophie) $8 \mathrm{mal}$,

*) "Ich habe mich gewöhnt, die Prüfung in der Weise vorzunehmen, dass ich im Dunkelzimmer den Kranken anweise, in der Richtung einer vor ibm stehenden Lampe unverwandt hinzusehen, sodann verdecke ioh ihm beide Augen mit den Händen und prüfe nan die Lichtreaction jedes Auges einzeln bei verdecktem zweiten Auge. Mit einer Convexlinse zwischen Daumen und Zeigefinger werfe ich dann plötzlich durch eine leichte seitliche Verschiebung: der bedeckenden Hand ein scharfes Flammenbild auf die Hornhaut des untersuchten Auges, so dass also die Retina, und zwar die Macula lutea in Zerstrenungskreison beleuchtet wird und das in einer Weise, bei welcher der betreffende Untersuchte gar nicht in der Lage ist, durch irgend eine Einstellung seines Auges ein scharfes Netzhautbild von der Beleuchtungsquelle zu bekommen; er unterlässt dementsprechend auch jeden Versuch für die Nähe zu accommodiren, trotzdem die benutzte Lichtquelle ziemlich nahe vor ihm steht und man dadurch eine bedeutende Lichtintensität gewinnt". Berliner klin. Wochensobr. 1886. No. 3. 
Statistisches und Klinisches zar Kenntniss d. paralyt. Geistesstörung. $\quad 517$

Beginnende neuritische Veränderungen $3 \mathrm{mal}$,

Specifische Veränderungen (Iritis etc.) $3 \mathrm{mal}$,

Aeussere Augenmuskellähmungen $8 \mathrm{mal}$,

Congenitale Anomalien $6 \mathrm{mal}$.

Ueber das Verhalten der Kniephänomene giebt folgende Tabelle Aufschluss.

T a b e 11 e XII.

Verhalten der Kniephänomene.

\begin{tabular}{c|c|c|c|c|c|c}
\hline & $\begin{array}{c}\text { Anzahl } \\
\text { der Fälle. }\end{array}$ & Erhalten. & $\begin{array}{c}\text { Fehit } \\
\text { beiderseitig. }\end{array}$ & $\begin{array}{r}\text { Fehlt } \\
\text { einseitig. }\end{array}$ & Gesteigert. & Lebhaft. \\
\hline 1887 & 42 & 17 & 8 & - & 16 & 1 \\
1888 & 42 & 11 & 7 & 2 & 18 & 4 \\
1889 & 58 & 6 & 8 & 2 & 39 & 3 \\
1890 & 65 & 4 & 11 & 1 & 45 & 4 \\
1891 & 37 & 4 & 8 & - & 23 & 2 \\
\hline & 244 & 42 & 42 & 5 & 141 & 14 \\
in pCt.: & - & 17,2 & 17,2 & 2,0 & 57,7 & 5,7
\end{tabular}

Eine Zusammenstellung dieser Ziffern mit den von Siemerling und A. Westphal gefundenen ergiebt Folgendes:

Ta belle XIII.

über das Verhalten der Kniephänomene in den versohiedenen Beobachtungsperioden.

\begin{tabular}{|c|c|c|c|c|c|c|}
\hline & $\begin{array}{c}\text { Erhalten } \\
\text { in: } \\
\text { pct. }\end{array}$ & $\begin{array}{l}\text { Beiderseitig } \\
\text { aufgehoben } \\
\text { in : } \\
\text { pCt. }\end{array}$ & $\begin{array}{c}\text { Einseitig } \\
\text { aufge- } \\
\text { hoben in: } \\
\text { pCt. }\end{array}$ & $\begin{array}{c}\text { Gesteigert } \\
\text { in: } \\
\text { pCt. }\end{array}$ & $\begin{array}{c}\text { Lebhaft } \\
\text { in: } \\
\text { pCt. }\end{array}$ & $\begin{array}{l}\text { Herab- } \\
\text { gesetzt in: } \\
\text { pCt. }\end{array}$ \\
\hline $\begin{array}{l}1877--86 \\
1887-91 \\
1891-93\end{array}$ & $\begin{array}{l}32 \\
17 \\
25\end{array}$ & $\begin{array}{l}26 \\
17 \\
22\end{array}$ & $\begin{array}{l}2 \\
2 \\
2\end{array}$ & $\begin{array}{l}34 \\
57 \\
49\end{array}$ & $\begin{array}{l}2 \\
5 \\
-\end{array}$ & $\frac{4}{2}$ \\
\hline $\begin{array}{c}\text { ins- } \\
\text { gesammt } \\
(537 \mathrm{Fälle})\end{array}$ & 23 & 21 & 2 & 49 & - & - \\
\hline
\end{tabular}

Ich lasse in gleicher Zusammenfassung eine Uebersicht über die Beziehungen zwischen Pupillenreaction und Kniephänomen folgen, wie sie sich in den einzelnen Beobachtungsperioden ergaben. 
Tabelle XIV.

\begin{tabular}{|c|c|c|c|c|c|c|c|}
\hline & 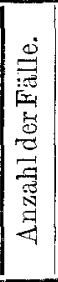 & 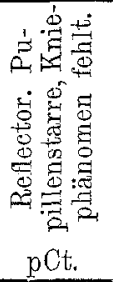 & 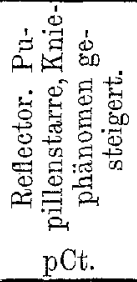 & 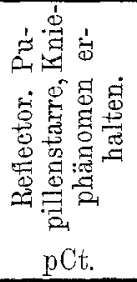 & 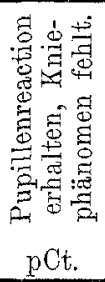 & 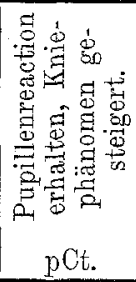 & 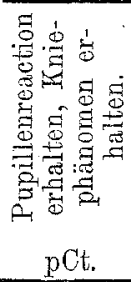 \\
\hline $\begin{array}{l}1877-86 \\
1887-91 \\
1891-93\end{array}$ & $\begin{array}{l}143 \\
178 \\
142\end{array} \mid$ & $\begin{array}{l}25 \\
13 \\
15\end{array}$ & $\begin{array}{l}22 \\
23 \\
23\end{array}$ & $\begin{array}{l}16 \\
13 \\
13\end{array}$ & $\begin{array}{l}5 \\
6 \\
9\end{array}$ & $\begin{array}{l}13 \\
33 \\
26\end{array}$ & $\begin{array}{l}17 \\
11 \\
14\end{array}$ \\
\hline
\end{tabular}

Es zeigt sich also eine Differenz zwischen Siemerling einerseits, Westphal und mir andererseits insofern, als bei uns die Fälle mit gesteigertem Kniephänomen ganz erheblich überwiegen, bei mir sogar noch mehr als bei Westphal. Wenn man hierbei auch berücksichtigen muss, dass bei der Entscheidung der Frage, ob ein Kniephänomen bereits als gesteigert oder nur als lebhaft zu bezeichnen ist, der subjectiven Auffassung des Untersuchers ein ziemlich weiter Spielraum bleibt, jedenfalls ein viel weiterer, als wenn es sich um den Nachweis des entgegengesetzten Verhaltens handelt, so glaube ich doch nicht, dass sich die in Rede stehende Differenz ausschliesslich hierdurch erklären lässt, da eine derartige Fehlerquelle bei der verhältnissmässig grossen Anzahl der Fälle keine sehr grosse Rolle spielt. Ausserdem würde die Thatsache dadurch unberührt bleiben, dass die Zahl der Fälle mit Verlust des Kniephänomens so viel seltener geworden ist. Es fragt sich nun, ob sich hieraus irgendwelche Schlussfolgerungen von Bedeutung ziehen lassen.

Bekanntlich ist die Steigerung der Kniephänomene in vielen Fällen, wenn auch nicht in allen, der klinische Ausdruck einer Affection der Pyramidenseitenstrangbahnen. Nun findet man, wie das neuerdings auch von Fürstner*) bestätigt ist, in der Mehrzahl der Fälle lebhafte oder gesteigerte Kniephänomene in den früheren Stadien der Krankheit. Hiermit stimmen anch die anatomischen Untersuchungen des letztgenannten Autors überein, durch welche in der überwiegen-

*) Fürstner, Zur Pathologie und patbologischen Anatomie der progressiven Paralyse, insbesondere über die Veränderungen des Rückenmarks und der peripheren Nerven. Dieses Archiv Bd. XXIV. S. 85, 86. 
den Majorität der Fälle eine combinirte Erkrankung der Seiten- und Hinterstränge, und unter diesen wiederum häufiger eine ausgedehntere Affection der Seiten-"als der Hinterstränge festgestellt wurde. Fürstner spricht die Ueberzeugung aus, dass bei der Mehrzahl der Fälle dieser Gruppe der pathologische Process seinen Ausgangspunkt von den Seitensträngen nimmt, und dass erst in einem späteren Stadium die Hinterstränge betheiligt werden.

Es wäre nun für meine Fälle von grossem Interesse gewesen, das weitere Verhalten der Kniephänomene zu verfolgen. Dies war leider aus äusseren Gründen nicht möglich, ebenso konnte ich nur in einer für die statistische Verwerthung zu kleinen Zahl die anatomische Untersuchnog des Rückenmarkes vornehmen. Jedenfalls wird aber die Erwägung nahe gelegt, ob sich nicht unter den von Westphal und mir beobachteten Fällen eine grössere Anzahl von in relativ frühen Krankheitsstadien Stehenden befunden hat, als unter Siemerling's Fällen. Dies würde zur Voraussetzung haben, entweder, dass die Kranken früher, d. h. kürzere Zeit nach dem Ausbruch der Erkrankung, zur Aufnahme gelangten, oder dass der Krankheitsverlauf überhaupt neuerdings ein langsamerer und milderer wäre. Beides trifft für meine Fälle nicht zu, wie bereits gezeigt worden ist (s. Tabelle VI. Dauer der Krankheit vor der Aufnahme), bezw. weiter unten gezeigt werden wird. Es würde also dann nur die Annahme übrig bleiben, dass der Krankheitsverlauf speciell mit Bezug auf die Rückenmarksbetheiligung in den letzten Beobachtungsjahren ein gutartigerer gewesen ist. Eine Erklärung hierfür vermag ich allerdings nicbt zu geben.

Auf die übrigen körperlichen Symptome gehe ich nicht ein; erwähnt sei nur, dass sich unter meinen Fällen auch die Eine der von König*) beschriebenen, anfallsweise an ganz passageren Sprachstörungen bei erbaltenem Bewusstsein leidenden Kranken befindet, bei welcher die Differentialdiagnose zwischen einem eigenartigen paralytischen Anfall and einer hypochondrischen bezw. hysterischen Complication einige Schwierigkeiten bereitete.

Zur Veranschaulichung des geistigen Verhaltens meiner Kranken dient zunächst eine allgemeine Tabelle, welche wiederum grössere Zeitabschnitte, und zwar unter Zugrundelegung des Alters zur Zeit des Todes zusammenfasst.

*) W. König, Ueber passagere Sprachstörungen bei progressiver Paralyse. Allg. Zeitschr. f. Psychiatrie 49. S. 145 ff. 
Tabelle XV.

\begin{tabular}{|c|c|c|c|c|c|c|}
\hline $\begin{array}{c}\text { Alter } \\
\text { zur Zueit des } \\
\text { Todes. }\end{array}$ & $\begin{array}{c}\text { Vorwiegend } \\
\text { tobsïchtig } \\
\text { erregt. } \\
\text { pCt. }\end{array}$ & $\begin{array}{c}\text { Vorwiegend } \\
\text { ägstlich oder } \\
\text { deprimirt oder } \\
\text { hypo- } \\
\text { chondrisch. } \\
\text { pCt. }\end{array}$ & $\begin{array}{l}\text { Vorwiegond } \\
\text { hallucina- } \\
\text { torisch ver- } \\
\text { wirrt. } \\
\text { pCt. }\end{array}$ & 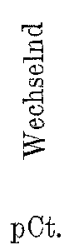 & 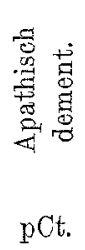 & 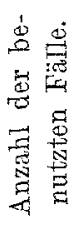 \\
\hline $\begin{array}{l}20-30 \text { Jahre } \\
30-45 \quad " \\
45-60 \quad "\end{array}$ & $\begin{array}{l}10,9 \\
24,7 \\
20,0\end{array}$ & $\begin{array}{l}-- \\
10 \\
5,7\end{array}$ & $\begin{array}{r}10,9 \\
11,1 \\
2,8\end{array}$ & $\begin{array}{l}- \\
8,6 \\
5,7\end{array}$ & $\begin{array}{l}77,7 \\
45,6 \\
65,7\end{array}$ & $\begin{array}{r}9 \\
81 \\
35\end{array}$ \\
\hline Im Mittel & 22 & 8 & 9 & 7 & 54 & 125 \\
\hline
\end{tabular}

Dieser Ueberblick lehrt, dass das Bild der apathischen Demenz in allen Altersklassen bei Weitem überwiegt. Ob dies wirklich, wie es nach der Tabelle den Anschein hat, bei den relativ jüngsten Kranken in einem noch so viel höheren Grade der Fall ist als bei den älteren, muss zweifelhaft bleiben, da die Zahl der zwischen dem 20. - 30. Lebensjahr Verstorbenen zu klein ist, um sichere Schlüsse zu gestatten. - Bei den relativ ältesten Kranken finden wir die tobsüchtigen Erregungszustände auch noch selten, bei den im mittleren Alter Stehenden etwas häufiger, hier sind aber ausserdem verhältnissmässig oft hypochondrische und andere Depressions-, ferner hallucinatorische Zustände notirt, auf die ich zum Theil noch zurückkomme.

Im Allgemeinen kann ich mich in Bezug auf den Charakter der psychischen Störung nach meinen Beobachtungen durchaus den bekannten Schilderungen anschliessen, wie sie zuerst von Sander, später auch von zahlreichen anderen Autoren und mit Bezug auf die paralytischen Frauen der Berliner Klinik besonders von Siemerling gegeben worden sind. Auch bei meinen Kranken waren Grössendelirien, allerdings meist mit einem dem weiblichen Sinn entsprechenden Stich in's Kleinliche, durchaus nicht selten, dieselben traten aber gewöhnlich nur episodisch auf und verschwanden rasch mit dem Fortschreiten der psychischen Schwäche. Auch Zustände heftigster Tobsucht traten nur relativ selten ein, ebenso wie solche tiefster hypochondrischer Verstimmung; immerhin wurden doch sehr charakteristische Fälle dieser und jener Gattung beobachtet, von denen ich weiter unten einige anführe. - Besonders betonen muss 
ich die ausserordentliche Häufigkeit leichterer hypochondrischer Verstimmungen bei meinen Fällen.

Ein nicht ganz unbedeutender Bruchtheil meiner Kranken war durch Eigenthumsverbrechen, unzüchtige Handlungen, Erregung öffentlichen Aergernisses etc. mit dem Strafgesetz in Conflict gerathen; darunter befand sich eine Kranke, welche mehrjährige Zuchthausstrafen, zuletzt in bereits zweifellos krankhaftem Zustande verbüsst hatte.

Ich muss hier mit einigen Worten auf eine Gruppe von Erscheinungen eingehen, welche $\mathrm{Knecht*}$ ) einige Male bei paralytischen Männern gesehen und beschrieben hat. Es sind dies Mischformen von "katatonischen" und paralytischen Symptomen und zwar unterscheidet Knecht 2 Gruppen: bei der einen soll die Krankheit als ausgesprochener melancholischer Stupor beginnen und monatelang unter dem Bilde eines solchen verlaufen, bis dann plötzlich eine rasch fortschreitende und zum Tode führende Paralyse in die Erscheinung tritt. Die andere Gruppe soll von Anfang die Symptome der gewöhnlichen Paralyse zeigen, welche dann später von einer „Katatonie“ abgelöst wird, während deren Bestehens indess wiederholt paralytische Anfälle auftreten können.

Für jede der beiden Formen führt Knecht je 2 Beispiele an, welche Männer betreffen. - Es hat sich nun weiterhin gezeigt, dass Andeutungen derartiger Erscheinungen im Verlaufe einer Paralyse nicht sehr selten sind; es finden sich z. B. in der Literatur zerstreut eine ganze Anzahl von casuistischen Mittheilungen, in denen des intercurrenten Vorkommens von Stupor Erwähnung geschieht, dabei handelt es sich ebensowohl um Männer als um Frauen. Auch Kräpelin erwähnt in seinem Lehrbuche, dass kataleptische Erscheinungen mit Flexibilitas cerea in der Benommenheit nach paralytischen Anfällen nicht allzu selten vorübergehend zu beobachten sind; hingegen erachtet er eine längere Zeit (Wochen und Monate) hindurch fortbestehende Katalepsie für selten and bezeichnet das gleichzeitige Vorhandensein der „besonderen Symptome der Kata-

*) Knecht, Ueber die katatonischen Erscheinungen in der Paralyse. Vortrag im psychiatrischen Verein zu Berlin 1885. Allg. Zeitschr. für Psych. Bd. 42. S. $331 \mathrm{ff}$. Vergl, auch den Aufsatz von Neisser: Ueber das Symptom der Verbigeration. Allg. Zeitschr. für Psych. Bd. 46.

**) Näcke, Ueber katatonische Symptome im Verlauf der Paralyse bei Frauen. Zeitșchr. f. Psych. Bd. 49. S. 51 ff. 
tonie" (Negativismus, Zwangsbewegungen, Verbigeration) als nur hier und da vorkommend.

In einem Aufsatze, welcher speciell die katatonischen Symptome im Verlauf der Paralyse der Frauen behandelt, betont $\mathrm{Näcke*}$ ) zunächst, dass auch bei dem weiblichen Geschlecht ebensowohl im Verlauf der Paralyse wie im Verlauf anderer Psychosen einzelne der als katatonische bezeichneten Symptome nicht selten anzutreffen seien; insbesondere hat er Verbigeration, automatische Bewegungen, Benommenheitszustände besonders nach den Anfällen wiederholt, wenn auch seltener als bei den Männern beobachtet. Dagegen hat er niemals bei den weiblichen Patienten solche Bilder gesehen, wie sie Knecht beschrieben hat. - Näcke giebt dann Kenntniss von drei weiblichen Paralytischen, bei denen wiederholt Zustände plötzlichen Stupors mit gespannnter Muskulatur auftraten, und zwar ohne directen Zusammenhang mit paralytischen Insulten. Es handelte sich um einen wirklichen Stupor, der aber meist nur wenige Stunden anhielt. Im Uebrigen zeigten die Fälle nichts Besonderes. Näcke betont dass keine Flexibilitas cerea bestand, sondern jeder passiven Bewegung Widerstand geleistet wurde.

Im Anschluss hieran sind auch einige Fälle meiner Beobachtung nicht ohne Interesse, die ich in gekürzter Form folgen lasse.

\section{Beobachtung 1 .}

Frau Emma R, 25 Jahre alt. - Keine Heredität, keine früheren Krankheitszeichen. - Seit 15 Jahren verheirathet, vor 9 Jahren syphilitisch in. ficirt, hat 3-4 mal abortirt, 2 Kinder klein verloren, 3 am Leben. - Am 26. December 1888 plötzlioher Ausbruch der Geisteskrankheit: Grössenideen, grosse Einkäufe, gemeingefährliche Handlangen. - Am 30. December 1888 Aufnahme in die Charité. Pat. ist hochgradig erregt, tobsüchtig, spricht fortwäbrend im Sinne ihrer Grössenideen, lässt sich nicht fixiren. - Körperliohe Untersuchnng bei der Unrube zunächst nicht möglich; später wurde gesteigertes Knie-Pbänomen, träge Licht-Reaction derPupillen und charakteristische Sprachstörnng gefunden. - Allmälig steigert sich die Erregnng noch; Pat., die Anfangs noch verständliche, wenn auch unsinnige Grössenideen äusserte, stösst jetzt oft längere Zeit nur eine Reihe unartikulirter Lante aus, macht allerhand sonderbare Bewegungen; beisst in die Matratze, steckt sich die Finger in den Mund, schlägt rbyihmisch gegen die Bettwand etc. - In den nächsten Tagen dasselbe Verhalten; dann etwas ruhiger, macht oft noch lange Zeit gewisse stereotype Bewegungen (Händeklatschen, sonderbare Gesticulationen). - Weiterhin wieder Tobsucht, paralytische Anfälle, Verfall. Am 14. März 1889 Exitris, - Typischer Sectionsbefund. Gesammtdauer der Krankeit 51/2 Monate. 


\section{Beobachtung 2.}

Johanna A., 39 Jahre alt, ledig. - Ueber erbliche Belastung, Vorleben etc. nichts Genaueres bekannt. Anfang 1891 erregt, begeht im Hause gemeingefährliche Verkehrtheiten, wird deshalb am 22. Februar 1891 in die Charité aufgenommen. - Bei der Aufnahme ganz verwirrt, tobt, lärmt, zerreisst ibre Sachen und stösst oft längere Zeit nur unartikulirte Laute aus, von denen ,hadubri-hadubri" etc. notirt ist. - Später werden erst selten, dann bäufger zusammenhängende Sätze geäussert. Dabei erweist sich die Sprache als eigenthümlich stotternd, aber nicht eigentlich paralytisch gestört; ausserdem macht Patientin allerhand sonderbare Bewegungen von stereotypem Charalter. Unter diesen ist besonders eine Bewegung der Hand gegen den Mund hin auffallend, welche zeitweise so oft wiederholt wird und sich so lebhaft gestaltet, dass eine Art ron Anfall zu Stande kommt.

Die körperliche Untersuchang, welche anfangs nicht möglich war, ergiebt: Differenz und fehlende Licht-Reaction der Pupillen. - Weiterhin nehmen die Aeusserungen der Patientin einen exquisit hypochondrischen Charakter an: Sie spricht von ,Zungenlähmung", ,Schlaganfall", zunächst in kurz abgerissener Weise, dann äussert sie zusammenhängende Wahnideen: ihr Urin sähe ans wie Chokolade, der Stublgang wie die Entleerungen rom Schaf, sei verkohlt und übelriechend; đie Leber sei wi $\theta$ eine Sobweineleber, voll Eiter, ein Stück Lunge sei ihr mit dem Strhlgang abgegangen etc.

Am 12. März 1891 nach Dalldorf überfübrt. Gesammtdauer der Krankheit unbekannt.

\section{Beobachtung 3 .}

Marie G., 30 Jahre alt, ledig. - Geringe hereditäre Belastung. Patientin ist bis 6 Monate vor ihrer Anfnahme ganz gesund gewesen; seitdem hat sie an Kopfschmerzen gelitten, ist nicht recht leistungsfähig und zurerlässig gewesen. Seit 5 Wochen vor der Aufnahme ist sie fast verstummt, antwortet nur ja und nein, muss gekämmt und gewaschen, auch gefüttert werden, wird zuweilen ganz vorübergehend erregt. - Einige Tage vor der Aufnahme absolut widerstrebend. Deshalb am 19. Febraar 1890 der Charité zugeführt. - In der Klinik heftigster Widerstand gegen Alles, spricht nicht, sieht sehr gespannt aus. Muss gefüttert werden, beisst dabei die Zähne fest zusammen.

Körperliche Untersuchung: Pupillen-Reaction rechts vorhanden, links träge (?). - Später dentliche Sprachstörung. Knie-Pbänomene normal.

Allmälig otwas zugänglicher, beginnt za sprechen. Ersoheint nur mässig dement; giebt keinen Grund für ihr bisheriges Verbalten an.

Am 6. März 1890 nach Dalldorf überführt.

Patientin ist daselbst verstorben; typiseher Sectionsbefand. Gesammtdaver der Krankheit: 7 Monate.

\section{Beobachtung 4.}

Minna E., verheirathet. 40 Jahre alt. - Keine Heredität. 3 Aborte. Patientin leidet seit October 1890 an Kopfschmerzen, ist reizbar und ver- 
gesslich geworden. Einige Tage vor der Aufnahme Verwirrtbeit, Grössenideen. - Aufnahme in die Charité am 31. März 1891. Die körperliche Untersucbung ergiebt: Papillen eng, lichtstarr. - Sprache etwas gestört. - Knie-Phänomen gesteigert. - Geistig: Erregung mit Grössenideen. - 8 Tage nach der Aufnahme, wahrscheinlich nach einem nicht bemerkten paralytischen Anfall verändertes Wesen: Patientin ist stamm, steht unbeweglich auf einem Fleck, antwortet gar nicht oder ganz leise ond zögernd. - Aengstlicher Gesichtsausdruck. - Mehrfache plötzliche impulsive Angriffe auf andere Kranke. Weiterhin öfters scheinbar willkürliche, aber storeotype Bewegungen, besonders der linken Extremitäten. - Nach einiger Zeit beginnt Patientin wieder lebhafter zu werden und zu sprechen: Sie äussert jetzt hypochondrische Ideen (habe kein Herz mehr und dergl.). - Am 30. April aus der Beobachtung gekommen. - Gesammtdauer der Krankbeit unbekannt.

\section{Beobachtung 5.}

Minna R., 39 Jahre alt, Kanfmannsfrau. - Keine Heredität. - Patientin ist syphilitisch inficirt worden. - Seit 2 Jahren im Anschluss an eine schwere körperliche Krankheit besteht grosse Erregbarkeit. - Seit 1 Abort (6 Monate vor der Aufnahme) zeigte sie ein stilles, unzugängliches Verhalten. Sie sass oder stand standenlang auf einer Stelle, starrte vor sich hin, sprach nicht, verweigerte die Nahrungsaufnahme. - Aufnahme am 24. Juli 1890. Patientin sträubt sich gegen Alles auf das Lebhafteste. Liegt ganz steif und zusammengekrümmt im Bett, lässt die einmal angenommene Stellung in keiner Weise passiv verändern. Verweigert die Nahrungsaufnahme, lässt keinen Urin. - Starrer, leerer Gesichtsausdruck.

Körperlich: Pupillen different, lichtstarr. - Kniepbänomen bei der bestehenden Spannung nicht sicher zu beurtheilen.

Nach 2 Tagen Nachlass der Spannung; die Extremitäten sind bei passiven Bewegungen sohlaff. - Noch keine sprachlichen Aeusserungen. - Allmälig zugänglicher, spricht noch wenig, ist aber sehr ängstlicher Stimmung.

Am 19. November 1890 ans der Beobachtung. - Gesammtdaner der Krankheit unbekannt.

\section{Beobachtung 6 .}

Marie H., verheirathet, 35 Jahre alt. - Keine Heredität. - Seit 1884 verheirathet. - 1 Entbindung. - Patientin ist doreh den Ehemann syphilitisch inficirt. - 1885 oin Krampfanfall nicht bekannter Art, vielloicht bysterisch.

1889 Beginu der jetzigen Krankheit: Auffallendes Benehmen. - Unnöthige Ausgaben. - Vernachlässigung der Wirthschaft. - Am 6. Juli 1889 erste Aufnabme in die Klinik. Pupillen different. - Lichtreaction erbalten - Kniephänomen gesteigert. - Keine dentliche Sprachstörung. 
Geistig heiterer Erregungszustand, der sich zeitweise zu Tobsucht und Zornausbrüchen steigert.

Im weiteren Verlaufe mehrfach Zustände von voräbergehendem Sprachverlust; Patientin drückt sich dann die Backen in querer Richtang zusammen und behauptet dadurch die Sprache wieder zu erlangen.

Am 27. Juni 1889 nach Dalldorf überführt; von hier im September 1890 beurlaubt, erschien sie ibrem Manne gesund, machte ihre Wirthschaft zur Zufriedenbeit, war ruhig, klagte nur zuweilen über Kopfschmerzen.

Mitte März 1891 ein paralytischer Anfall mit 14 Tage andauerndem Sprachyerlust; seit dieser Zeit stilles Wesen, fast gar keine sprachlichen Aeusserungen.

Am 8. Maj 1891 zweite Aufnahme in die Charité. - Patientin ist äusserst widerstrebend, lässt sich schieben und verharrt, sich selbst überlassen, in einer Stellung mit gesenktem Kopfe, herausfliessendem Speichel ganz unbeweglich. Bei allen passiven Bewegungen ist ein sebr hochgradiger Widerstand zu überwinden. - Die Glieder verharren kurze Zeit in den ihnen gegebenen Stellungen. Patientin spricht gar nicht, muss gefüttert werden. Nadelstiche rufen nur eine geringe Reaction hervor; erst bei Stichen in's Nasenseptum wendet Patientin den Kopf etwas energischer fort, erhebt ihn etwas, lässt ihn dann aber auf die Brust geneigt stehen.

Körperlicb: Pupillon different, Lichtreaction links gering, rechts orloschen. - Kniephänomen gesteigert.

Am 11. Juni 1891 nach Dalldorf überführt.

Hier ist Patientin am 20. Jani 1892 gestorben.

Section ergab die charakteristischen Veränderungen. Gesammtdauer der Krankheit 3 Jahre.

\section{Beobachtung 7 .}

Martha H., 28 Jahre alt, Prostituirte. - Patientin hat lange unter sittenpolizeilicher Controle gestanden. - Sie soll erst seit einigen Wochen krank sein, hat zunächst auf einer inneren Abtheilung gelegen, ist am 18. April 1890 wegen eines Depressionszustandes nach der Irrenabtheilung verlegt worden. - Die körperliche Untersuchung ergiebt zunächst ansser einem specifischen Geschwür an der Unterlippe nichts Besonderes. - In geistiger Beziehung besteht tiefe Depression; Patientin spricht wenig, äussert aber Selbstanklagen.

19. April. Sträubt sich heftig beim Essen; wird Abends ängstlich eraregt, macht sich lebhafte Vorwürfe.

20. April. Liegt heute regungslos; nimmt keine Nahrung, lässt die ihr beigebrachten Flüssigkeiten aus dem Munde herauslaufen.

21. April. Passiver Widerstand bei Allem.

23. April. Zeitweise zugänglicber, antwortet dann leise, zu anderen Zeiten wieder ganz stumm; alle Glieder starr, lassen sich nur mit Mühe bewegen, 
25. April. Aengstlich erregt, Selbstanklagen, bezeichnet ihren Körper als "schlecht", spricht von Einem, der immer "hinter ihr her" sei. Schreit Aeusserungen dieses Inhaltes laut heraus.

27. April. Tiefer Stupor. Liegt ganz still mit nach vorn links geneigtem Kopfe. Lässt die passiv erhobenen Glieder erst langsam wieder sinken. - Widerstand bei allen Bewegungen. Stumm. Nahrungsverweigerung.

2. Mai. Wieder lebhafter, spricht einige zusammenhängende Sätze.

6. Mai. Tiefer Stupor. - Presst die Zähne zusammen, spricht nicht. Macht sich nass. Liegt ganz regungslos mit auf der Brust gekreuzten Armen, stränbt sich gegen Alles.

18. Mai. Häufig rasch verfliegende Röthung des Gesichtes.

20. Mai. Liegt ganz still und regungslos. - Sehr starker Schweissausbruch.

25. Mai. Vorübergehend erregt, will hinaus, murmelt Unverständliches. Beim Gehen fällt grosse Unsicherheit auf. - Pupillen jetzt different, die linke reagirt träge auf Licht. - Kniephänomen nur schwach hervorzurufen. - Nach kurzer Zeit wieder ganz starr und stumm.

2. Juni. Derselbe Wechsel der Ersoheinungen. Beim Sprechen jetzt charakteristische Störung und Beben der Gesichtsmuskeln. - Lacht zuweilen blödsinnig. Anscheinend rasch fortschreitende Demenz.

1. September. Bisher keine wesentliche Aenderung. Hente paralytischer Anfall, darnach benommen, lässt den passiy erbobenen rechten Arm eine Zeit lang stehen.

Hochgradige Demenz. - Patientin vermag in der Zeit, wo sie mittheilsamer ist, nichts über den Grund ihres Verhaltens anzugeben.

Am 16. October Ueberführung nach Dalldorf. - Hier wurden stuporöse Zustände nicht mehr beobachtet. Pupillenreaction auf Licht sehr gering. Kniephänomen stark herabgesetzt. - Anfang 1891 Verwirrungszustand, Marasmus; Exitus am 31. März 1891.

Seotion ergiebt den typischen Befund.

Gesammtdauer der Krankheit über 1 Jahr.

Wie man sieht, ist auch unter diesen Fällen keiner, welcher einer der beiden von $\mathrm{Knecht}$ beschriebenen Formen vollständig entspräche, dieselben müssen also bei den Frauen noch seltener sein als bei den Männern. Nur eine Beobachtung, die letzte der mitgetheilten, ist darunter, welche eine gewisse Aebnlichkeit mit Knecht's erstem Typus erkennen lässt. Es handelte sich bei dieser Kranken im Anfang um ein Gemisch von melancholischen und „katatonischen" Erscheinungen, als deren gemeinsame Grundlage erst nach einiger Zeit die progressive Paralyse nachgewiesen werden konnte. Im Uebrigen kann aber meines Erachtens bei den von mir mitgetheilten Fällen von einem bestimmten Typus, der die Aufstellung einer besonderen klinischen Form rechțertigen würde, keine Rede sein. Wir 
sehen nur einzelne der sogenannten katatonischen Symptome da und dort ziemlich regellos und mehr oder weniger deutlich ausgesprochen auftreten, wie das auch bei anderen Psychosen zu beobachten ist. Immerhin scheinen auch diese Fälle, die ich noch um eine Anzahl ähnlicher vermehren könnte, nicht gerade häufig zu sein. Es handelte sich bei meinen Kranken in erster Linie um mehr oder weniger intensive Zustände motorischer Hemmung, die sich einerseits in der Körperhaltung und dem Charakter der Bewegungen, andererseits in der sehr geringen oder auch ganz fehlenden sprachlichen Reaction kundgab. Sehr selten zeigte sich das Symptom der Katalepsie (nur in $\mathrm{zwei}$ meiner Beobachtungen (No. 6 und 7 ) und $\mathrm{zwar}$ beide Male längere oder kürzere Zeit nach einem paralytischen Anfalle). Flexibilitas cerea habe ich in keinem Falle beobachtet. - Dagegen waren sogenannte "negativistische ${ }^{c}$ Erscheinungen relativ häufig vorhanden und zeigten sich darin, dass die Kranken sich gegen Alles, was mit ihnen vorgenommen werden sollte, insbesondere auch gegen die $\mathrm{Zu}$ führung von Nahrung, in der heftigsten Weise sträubten, ohne dass übrigens bereits eine besonders hochgradige Demenz vorhanden gewesen wäre. - Das Symptom der "Verbigeration" war nur in einem Falle (Beobachtung 2) vorübergehend vorhanden. Es ist zwar auch in Beobachtung 1 davon die Rede, dass bei einer sehr erregten Kranken zeitweise ganz unzusammenhängende Worte oder unarticulirte Laute sinnlos an einander gereiht wurden, wir müssen aber von der eigentlichen Verbigeration scharf trennen die Aensserungsweise derjenigen Kranken, welche in Folge hochgradiger Erregung und dementsprechend vorhandener überreichlicher und übermächtiger Bewegungsimpulse einfach keine Zeit finden, ihren Gedanken einen verständlichen Ausdruck zu verleihen. - In einigen meiner Fälle wurden endlich gewisse einförmige Bewegungen beobachtet, die man wohl als „stereotype" bezeichnen kann.

Was nun die Deutung der hier aufgeführten Erscheinungen betrifft, so muss berücksichtigt werden, dass bei allen meinen Kranken die depressive Gemüthslage vorherrschte und dass bei einer verbältnissmässig grossen Zabl der Fälle hypochondrische Vorstellungen sicher vorhanden, bei den übrigen aber mindestens nicht auszuschliessen waren. Bekanntlich aber kommen bei der Hypochondrie überhaupt und auch speciell bei der Hypochondrie der Paralytischen (auch der weiblichen, wie durch eine Reihe von Beobachtungen festgestellt ist) nicht selten anfallsartige Erscheinungen innerhalb der motorischen Sphäre vor, welche meist nachweisbar psychisch bedingt sind und oft die frappanteste Aehnlichkeit mit gewissen der „Kata- 
tonie" zugerechneten Symptomen haben. - Ich will mich an dieser Stelle auf keine Erörterungen über die Frage einlassen, ob die Aufstellung eines selbstständigen, als Katatonie zu bezeichnenden Krankheitsbildes gerechtfertigt erscheint, muss aber doch meiner Ueberzengung dahin Ausdruck geben, dass die Hypochondrie bei der Entwickelung aller der hier in Frage stehenden Zustände eine viel bedeutendere Rolle spielt, als im Allgemeinen angenommen wird.

Es bedarf noch einiger Bemerkungen über die Daner der Krankheit. - Im September vorigen Jahres konnte ich über das Schicksal meiner 256 Fälle folgendes feststellen: Es waren noch am Leben, meist in Filialen der Dalldorfer Anstalt, 21 Kranke; in die Familie entlassen waren 45 Kranke, über deren Schicksal ich nichts weiss. 8 Frauen waren nach einer anderen Anstalt überführt, 182 waren gestorben.

Für eine Anzahl der letzteren*) habe ich, soweit die anamnestischen Unterlagen genügten, die Gesammtdauer der Krankbeit ausgerechnet. Dabei ergab sich unter gleichzeitiger Berücksichtigung des Alters zur Zeit des Todes folgendes:

Tabelle XVI.

\begin{tabular}{|c|c|c|}
\hline $\begin{array}{l}\text { Alter } \\
\text { zur Zeit des } \\
\text { Todes. }\end{array}$ & $\begin{array}{l}\text { Durchschnittliche Dauer der Krank- } \\
\text { heit vom Auftreten der ersten deut- } \\
\text { lichen Symptome an gerechnet. }\end{array}$ & $\begin{array}{l}\text { Anzahl der zu dieser Be- } \\
\text { rechnung benutzten Fälle. }\end{array}$ \\
\hline \multirow[t]{2}{*}{$\begin{array}{l}20-30 \text { Jahre } \\
30-35 \% \\
35-40 " \\
40-45 \% \\
45-50 " \\
50-55 \% \\
55-60 " \\
60-70 "\end{array}$} & $\begin{array}{l}20 \text { Monate } \\
24,5 \quad " \\
22 \quad " \\
25 \quad " \\
33 \quad " \\
22 \quad " \\
14 \quad " \\
26 \quad " \\
\end{array}$ & $\begin{array}{c}7 \\
11 \\
22 \\
23 \\
10 \\
12 \\
3 \\
4] \\
\end{array}$ \\
\hline & 23,3 Monate & 92 \\
\hline
\end{tabular}

Die durchschnittliche Dauer der Anstaltsbehandlung wird durch die Tabelle XVII veranschaulicht.

*) Die Fälle, in denen den deutlichen Erscheinungen der progressiven Paralyse einzelne Störungen, wie Angenmuskellähmungen, Tabes etc. viele (bis 13) Jahre vorausgegangen waren, sind als exceptionelle bier nicht mitgerechnet. 
Tabelle XVII.

\begin{tabular}{|c|c|c|}
\hline $\begin{array}{l}\text { Alter } \\
\text { zur Zeit des } \\
\text { Todes. }\end{array}$ & $\begin{array}{l}\text { Durchschnittsdauer der Anstalts- } \\
\text { handlung. vom ersten Eintritt an } \\
\text { gerechnet (Unterbrechungen ver- } \\
\text { nachlässigt). }\end{array}$ & $\begin{array}{l}\text { Anzahl der zu dieser Be- } \\
\text { rechnung benutzten Fälle. }\end{array}$ \\
\hline \multirow[t]{2}{*}{$\begin{array}{l}20-30 \text { Jahre } \\
30-35 \quad " \\
35-40 \quad " \\
40-45 \Rightarrow \\
45-50 " \\
50-55 " \\
55-60 " \\
60-70 \quad "\end{array}$} & $\begin{array}{rl}6 & \text { Monate } \\
15 & " \\
10 & " \\
9 & " \\
11 & " \\
8 & " \\
5 & " \\
8 & "\end{array}$ & $\begin{array}{c}9 \\
20 \\
33 \\
28 \\
15 \\
17 \\
3 \\
3]\end{array}$ \\
\hline & 9 Monate & 128 \\
\hline
\end{tabular}

Endlich giebt Tabelle XVIII. wieder eine zusammenfassende Uebersicht über die Dauer der Krankheit und diejenige des Anstaltsaufenthaltes nach grösseren Altersabschnitten. Dabei sind die über 60 Jahre alten Kranken nicht mitgezählt.

\section{Tabelle XVIII.}

\begin{tabular}{|c|c|c|c|c|}
\hline $\begin{array}{l}\text { Alter } \\
\text { zur Zeit des } \\
\text { Todes. }\end{array}$ & $\begin{array}{l}\text { Durchschnittl. Dauer der } \\
\text { Krankheit vom Auftreten der } \\
\text { ersten deutl. Symptome an. }\end{array}$ & $\mid \begin{array}{c}\text { Anzahl } \\
\text { der } \\
\text { Fälle. }\end{array}$ & $\begin{array}{c}\text { Durchschnittl. Dauer } \\
\text { der } \\
\text { Anstaltsbehandlung. }\end{array} \mid$ & $\begin{array}{l}\text { Anzahl } \\
\text { der } \\
\text { Fälle. }\end{array}$ \\
\hline $\begin{array}{l}20-30 \text { Jahre } \\
30-45 " \\
45-60 "\end{array}$ & $\begin{array}{lc}21 & \text { Monate } \\
23,6 & \\
25 & \#\end{array}$ & $\begin{array}{r}7 \\
56 \\
25\end{array}$ & $\begin{array}{c}5,9 \text { Monate } \\
10,9 \quad " \\
9\end{array}$ & $\begin{array}{r}9 \\
81 \\
35\end{array}$ \\
\hline
\end{tabular}

Es ergiebt sich somit eine durchschnittliche Gesammtdauer der Krankheit von noch nicht 2 Jahren (23,3 Monate); Siemerling fand bei 34 Fällen, in denen der Beginn der Erkrankung durch eine genügende Anamnese festgestellt werden konnte, eine durchschnittliche Dauer von 2,5 Jahren, auch noch eine ausserordentlich niedrige Ziffer, welche aber, wie man sieht, die meinige nicht unbedeutend übertrifft. Ich habe deshalb für meine Fälle noch eine zweite Berechnung angestellt, wobei ich zweifelhafte Fälle so weit als irgend möglich zurückdatirt habe. Aus dieser Zusammenstellung, bei welcher 84 Fälle verwerthet wurden, ergiebt sich aber eine nur wenig höhere Ziffer, nämlich eine durchschnittliche Gesammtdauer von 2,3 Jahren, also ungefähr dieselbe wie bei Siemerling. - Ascher fand bei 
der Berechnung für die männlichen Paralytischen eine durchschnittliche Gesammtdauer von 26 Monaten. Wenn nun auch trotz möglichst sorgfältiger Anamnese häufig der Zeitpunkt des Krankheitsbeginnes nur schätzungsweise fixirt werden kann, so geht doch aus Siemerling's und meinem ziemlich übereinstimmenden Resultat hervor, dass man, wenigstens für Berlin, nicht von einem langsameren Verlauf der Paralyse bei den Frauen sprechen kann, ausserdem scheint es nach meiner Berechnung, als führte die Krankheit in neuerer Zeit etwas rascher zum Tode als früher. - Dies spricht sich auch in einer Differenz aus, welche zwischen Siemerling und meinen, die Daner des Anstaltsaufenhaltes betreffenden Zahlen besteht. (Siemerling fand eine durchschnittliche Dauer von 1,4 Jahren, ich eine solche von 9 Monaten). Diese letzten Ziffern können natürlich auf unbedingte $\mathrm{Zu}$ verlässigkeit Anspruch machen und lassen, da im Allgemeinen einem längeren Krankheitsverlauf auch ein längerer Anstaltsaufenthalt und umgekehrt entspricht"), immerhin einen Schluss auf die Richtigder anderen oben angegebenen Ziffern zu.

Aus Tabelle XVIII. ergiebt sich ferner, dass die durschschnittliche Krankheitsdaner mit dem Lebensalter zunimmt, wir sehen, dass dieselbe für die höchste Altersstufe sich um 4 Monate höher stellt als für die niedrigste; dies stimmt mit den von Ascher für die Männer gefundenen Ziffern durchaus überein.

Im Speciellen ist noch zu bemerken, dass sich unter meinen Fällen 18 befanden, welche innerhalb eines Jahres tödtlich verliefen. Von diesen gehörten 3 der ersten der 4 oben bei Besprechung der Syphilis unterschiedenen Gruppen, ferner 6 der zweiten, 3 der dritten, 4 der vierten Gruppe an, wärend die beiden letzten Fälle dort nicht mitgezählt worden sind. Diese Zahlen sind zu klein, um daraus auf irgendwelche Differenzen in der Krankheitsdauer, je nachdem Syphilis vorhanden war oder nicht, zu schliessen. - Ich habe deshalb für jede der genannten 4 Gruppen die Fälle zusammengestellt, in denen die Gesammtdauer bis zum Tode bekannt war. Daraus ergiebt sich für Gruppe I eine durchschnittliche Krankheitsdaner von 1,9 Jahren (14 Fâlle), für Gruppe II 1,7 Jahre (19 Fälle), für Gruppe III 2,6 Jahre (17 Fälle), endlich für Gruppe IV 2,8 Jahre (7 Fälle). Es scheint hiernach die Paralyse bei meinen Kranken mit sicherer oder böchstwahrscheinlicher Syphilis schneller verlaufen zu sein als bei den übrigen, doch darf man auch dies nicht verallgemeinern, so lange nicht grössere Zahlen vorliegen.

*) S. die betreffende Bomerkung bei Aschor J. o. S. 6. 
Die Fälle mit vorausgegangener Syphilis und die ohne solche zeigten weder in Bezug auf die geistigen noch in Bezug auf die körperlichen Symptome wesentliche Verschiedenheiten; insbesondere konnte ich die Erscheinungen der Hinterstrangserkrankung bei den Kranken der ersteren Gattung nicht häufiger nachweisen als bei denen der letzteren.

Zum Schlusse gebe ich noch einen Ueberblick über das Verhältniss zwischen Lebensalter und erblicher Belastung (Tabelle XIX.). Dabei habe ich zunächst diejenigen Fälle zusammengestellt, bei denen mir das Alter zur Zeit des Todes bekannt war; weil aber die betreffenden Zahlen insbesondere für die früheste Altersstufe (20-30 Jahre) zu klein ausfielen, habe ich auch eine Serie von Fällen berücksichtigt, in denen das Alter zur Zeit der Aufnalıme bekannt war (Tabelle XX.). Trotz dieses verschiedenen Eintheilungsprincips lassen sich doch beide Tabellen zur Beantwortung derselben Frage, ob nämlich die erbliche Belastung bei den jüngeren Kranken hänfiger anzutreffen ist als bei den älteren, gemeinsam verwerthen.

Tabell e XIX.

\begin{tabular}{l|c|c|c|c}
\hline $\begin{array}{c}\text { Alter } \\
\text { zur Zeit des } \\
\text { Todes }\end{array}$ & Belastet. & Nicht belastet. & $\begin{array}{c}\text { Zahl der be- } \\
\text { nutzten Fälle. }\end{array}$ & $\begin{array}{c}\text { Procentziffer } \\
\text { der erblich } \\
\text { Belasteten. }\end{array}$ \\
\hline $20-30$ Jahre & 3 & 1 & 4 & 75 \\
$30-45 "$ & 23 & 15 & 38 & 60,5 \\
$45-60 "$ & 7 & 8 & 15 & 46,6
\end{tabular}

Tabelle XX.

\begin{tabular}{c|c|c|c|c}
\hline $\begin{array}{c}\text { Alter } \\
\text { zur Zeit der } \\
\text { Aufnahme. }\end{array}$ & Belastet. & Nicht belastet. & $\begin{array}{c}\text { Zahl der be- } \\
\text { nutzten Fälle. }\end{array}$ & $\begin{array}{c}\text { Procentziffer } \\
\text { der erblich } \\
\text { Belasteten. }\end{array}$ \\
\hline $\begin{array}{l}20-30 \text { Jahre } \\
30-45,\end{array}$ & 2 & - & 2 & 100 \\
$45-60 \%$ & 15 & 23 & 38 & 39,4 \\
1 & 11 & 15 & 26,6
\end{tabular}

Wenn auch die Procentziffer der erblich Belasteten in der jüngsten Altersstufe wahrscheinlich zu hoch ausfällt, so scheint hiernach doch eine stetige Abnachme der erblich Belasteten mit dem zunehmenden Alter stattzufinden. Dieses Resultat würde mit dem von Ascher für die Männer gefundenen übereinstimmen. 
Es ergeben sich aus dem Vorstehenden die folgenden Schlussfolgerungen, welche aber, wie hier besonders betont werden muss, zum Theil nur eine locale Gültigkeit haben:

1. Nach den Aufnahmeziffern der Charité berechnet, verhält sich die Anzahl der weiblichen zu der der männlichen Paralytischen wie $1: 3,5$.

2. Die Anzabl der wegen progressiver Paralyse in die Königl. Charité aufgenommenen weiblichen Patienten hat in dem Zeitraum von 1887-1890 sowohl absolut, als auch im Verhältniss zu der Zahl der nicht paralytischen Geisteskranken zugenommen und zwar in stärkerem Masse, als es der weiblichen Bevölkerungszunahme Berlins entspricht. - Man darf hieraus für Berlin auf eine Zunahme der weiblichen Paralyse überhaupt schliessen.

3. Das bevorzugte Alter für die paralytische Erkrankung ist die zweite Hälfte des 4. Lebensdecenniums (36.-40. Jahr), also die präklimakterische Zeit.

4. Die von Siemerling constatirte Thatsache, dass Ausbruch der Erkrankung und Aufnahmebedürftigkeit allmälig mit einem jngendlicheren Alter zusammenfällt, lässt sich auch weiterhin nachweisen.

5. Unter den weiblichen Paralytischen überwiegen die Verheiratheten bei Weitem. - Die Betheiligung der Prostituirten erweist sich andauernd als eine verhältnissmässig sehr geringe.

6. Die ätiologischen Momente zerfallen in vorbereitende und auslösende. - Unter den ersteren ist die Heredität nur von allgemeiner Bedeutung, und spielt keine besondere Rolle, wenn auch anscheinend bei den jugendlichen Paralysen noch eine etwas grössere als bei den älteren. - Hingegen ist die venerische Infection als das vornehmste, speciell zur Paralyse disponirende Moment anzusehen. - Mit ihr zusammen oder seltener ohne sie können andere, die geistige oder körperliche Widerstandsfähigkeit chronisch schwächende Momente, in wechselnden Combinationen mit einander, in ähnlicher Weise vorbereitend wirken (sociale und psychische Ursachen einer-, unzweckmässige Lebensweise im weitesten Sinne andererseits). Die acut einwirkenden Schädlichkeiten (insbesondere auch Traumen) kommen in dieser Hinsicht nur ausnahmsweise in Betracht.

Dieselben repräsentiren vielmehr die wichtigsten aus- 
Statistisches und Klinisches zur Kenntniss d. paralyt. Geistesstörung. 533

Jösenden Ursachen, welche mannigfaltigster Art sein können.

7. Von den körperlichen Symptomen zeigt die Häufigkeit der reflektorischen Pupillenstarre eine grosse Constanz; sie findet sich in 50 pCt. der Fälle. - Den Fällen mit HinterstrangSymptomen gegenüber überwiegen in neverer Zeit diejenigen mit vorherrschenden Seitenstrang-Symptomen viel bedeutender als früher, ohne dass sich dies in befriedigender Weise erklären liesse.

8. Bei den weiblichen Paralytischen sind Fälle von sogenannter klassischer Paralyse selten; hingegen kommen intercurrent Grössendelirien sehr bäufig vor; auch hypochondrische Symptome sind meist nicht sehr ansgesprochen, aber keineswegs selten zu beobachten. - Der Grundcharakter der psychischen Störung ist im Allgemeinen der einer progressiven Demenz.

9. Die Krankheitsdauer ist keine längere als die der Männer; sie stellt sich durchschnittlich auf nicht ganz $2 \frac{1}{2}$ Jahre. Der Krankheitsverlauf scheint, vom Eintritt in die Anstalt an gerechnet, in der neweren Beobachtungsperiode ein schnellerer zu sein als in der älteren.

Herrn Geheimrath Jolly spreche ich für die freundliche Ueberlassung der dieser Zusammenstellung zu Grunde liegenden Krankengeschichten meinen verbindlichsten Dank aus. 